\title{
Computer applications for prediction of protein-protein interactions and rational drug design
}

This article was published in the following Dove Press journal:

Advances and Applications in Bioinformatics and Chemistry

9 November 2009

Number of times this article has been viewed

\author{
Solène Grosdidier ${ }^{1}$ \\ Max Totrov² \\ Juan Fernández-Recio' \\ 'Life Sciences Department, Barcelona \\ Supercomputing Center, Barcelona, \\ Spain; ${ }^{2}$ Molsoft LLC, La Jolla, CA, USA
}

\begin{abstract}
In recent years, protein-protein interactions are becoming the object of increasing attention in many different fields, such as structural biology, molecular biology, systems biology, and drug discovery. From a structural biology perspective, it would be desirable to integrate current efforts into the structural proteomics programs. Given that experimental determination of many protein-protein complex structures is highly challenging, and in the context of current high-performance computational capabilities, different computer tools are being developed to help in this task. Among them, computational docking aims to predict the structure of a protein-protein complex starting from the atomic coordinates of its individual components, and in recent years, a growing number of docking approaches are being reported with increased predictive capabilities. The improvement of speed and accuracy of these docking methods, together with the modeling of the interaction networks that regulate the most critical processes in a living organism, will be essential for computational proteomics. The ultimate goal is the rational design of drugs capable of specifically inhibiting or modifying protein-protein interactions of therapeutic significance. While rational design of protein-protein interaction inhibitors is at its very early stage, the first results are promising.
\end{abstract}

Keywords: protein-protein interactions, drug design, protein docking, structural prediction, virtual ligand screening, hot-spots

\section{Introduction}

Protein-protein interactions (PPI) are involved in most of the essential processes that occur in living organisms, such as cellular communication, immunological response, and gene expression control. A detailed energetic and structural knowledge of these interactions is necessary to understand the complex regulatory and metabolic interaction networks that occur in living organisms, with the ultimate goal of designing drugs for blocking or modifying interactions of therapeutic interest. Thus, targeting PPI of therapeutic interest with small-molecule compounds is becoming the Holy Grail of drug discovery. A number of experimental and computational methods have been reported to contribute to all the stages of the drug discovery process targeting PPI. High-throughput experimental methods, such as coexpression analysis ${ }^{1}$ and the yeast two-hybrid test, ${ }^{2}$ may be used to establish an interaction, and random mutagenesis ${ }^{3}$ to locate the interaction surfaces. Finally, X-ray crystallography and/or nuclear magnetic resonance (NMR) provide the most detailed structural information of the atomic interactions in a protein-protein complex. However, although the number of three-dimensional (3-D) protein structures deposited in
Correspondence: Juan Fernandez-Recio Life Sciences Department, Barcelona Supercomputing Center, C/Jordi Girona 29, 08034 Barcelona, Spain

Tel +34934137729

Fax +34 934I3772I

Email juanf@bsc.es 
the Protein Data Bank (PDB) $)^{4}$ is rapidly growing, only a small fraction of numerous protein-protein complexes, frequently transient, has been experimentally characterized so far. The increasing availability of high-performance computing has favored the development of computer tools that can help in this task.

Computational prediction of a protein-protein complex geometry from the 3-D coordinates of the individual proteins involved has a relatively short history. ${ }^{5}$ Early docking methods used purely geometrical criteria to evaluate the resulting solutions, and considered the conformation of the molecule side-chains as fixed (rigid-body assumption). While this approach demonstrated the ability to rebuild a protein-protein complex from its already mutually adjusted subunits, ${ }^{6,7}$ it was not accurate enough to model the induced fit of the interacting surfaces upon binding, and therefore the prediction results were clearly poorer when using the uncomplexed subunits. ${ }^{8}$ In order to perform more realistic simulations, recently developed docking methods include interface explicit or implicit flexibility, ${ }^{9,10}$ and a more accurate energy function. ${ }^{11}$ While a $100 \%$ reliable automated prediction of the association of two proteins is beyond the reach of current methods, advances in energy calculations and in global minimization algorithms, together with the increasing availability of computing power, may lead to useful predictions at a proteomic scale in the next few years.

The development of computational methods to model protein-protein docking, identify promising binding pockets, and predict protein-ligand association will facilitate the discovery of small molecules capable of inhibiting or modifying PPI, a major new challenge in drug design. We can envisage a general strategy for a multidisciplinary drug discovery process that targets PPI of therapeutic interest, involving four major stages (Figure 1). In the following sections each of these stages will be discussed in detail, with the emphasis on the computerized techniques (Table 1).

\section{Identification of PPI of biomedical importance}

A plethora of biochemical and genetic experiments, such as cross-linking, co-immunoprecipitation and co-fractionation by chromatography, among others, have been traditionally used to establish specific interactions between proteins. Biophysical assays have been also developed to experimentally measure kinetic and thermodynamic binding constants between two given proteins. ${ }^{12-16}$ From all the experimental methods, the yeast two-hybrid assay ${ }^{2}$ and correlation of mRNA expression profiles ${ }^{17}$ have propelled large-scale detection of PPI. ${ }^{1,18,19}$

In recent years, with all the available information derived from the genome sequencing projects, several computational tools have been applied to find and recognize PPI from genome sequences at a proteomic level. Analysis of co-evolution of proteins ${ }^{20}$ and gene fusion events ${ }^{21,22}$ can be used to detect putative PPI. A well-known study described the use of combination of techniques (correlated evolution, correlated mRNA expression profiles, and domain fusion patterns) to find 93,750 pairwise links between 4,701 (76\%) functionally related yeast proteins, from which 4,130 links (between 1,223 proteins) were of the 'highest confidence' (validated by direct experimental techniques or by two of the three prediction techniques). ${ }^{23}$ Other methods are based on interacting domains, ${ }^{24}$ interacting motifs, ${ }^{25}$ and a variety of criteria such as similarity of phylogenetic trees, ${ }^{26}$ protein interaction network topology, ${ }^{27}$ signature products ${ }^{28}$ or genome-wide coevolutionary networks. ${ }^{29}$ There are some good recent reviews that give a complete view of the currently available methods to identify PPI. ${ }^{30-33}$

Other computational approaches focus on mining the literature, the whole 'googleome,' for PPI. A system for automatic detection of PPI extracted from scientific abstracts was able to rebuild key interactions of the Drosophila cell cycle control for 33 of the 91 protein names used in the bibliography screening. ${ }^{34}$ A similar system, based on a general-purpose information extraction engine, identified interactions between two proteins from Medline abstracts with an accuracy of $77 \%$ and a coverage of $58 \%$ of the total interactions. ${ }^{35}$ Another method used discriminating words to identify Medline abstracts that described protein interactions, with an accuracy of $>77 \%$ and a coverage of $\sim 50 \%$ (or $100 \%$ of accuracy with a coverage of $\sim 30 \%$ ). ${ }^{36}$ A new text-mining method (PIE: Protein Interaction information Extraction system) is available on the web to extract PPI from literature (http://pie.snu.ac.kr/). This tool, consisting on an article filter followed by a sentence filter, has been trained on the BioCreAtIvE II workshop dataset, enriched by other selected known-interactions. Using a 10 -fold cross validation and 0.5 probability cutoff, the method showed a precision of $87.4 \%$ for the article filter, and $92.1 \%$ for the sentence filter. ${ }^{37}$

All the experimental and computational data on existing PPI were soon organized in various public databases: YPD and WormPD - Yeast and Caenorhabditis elegans Proteome Databases; ${ }^{38}$ MIPS - Munich Information Center for Protein Sequences ${ }^{39}$ DIP - Database of Interacting Proteins; ${ }^{40}$ 


\section{Protein-protein interaction identification and validation}

- Biochemical and genetic experiments (cross-linking; co-immunoprecipitation; yeast two-hybrid; co-expression profiles...)

- Genome analysis (co-evolution; gene fusion...)

- Biological validation

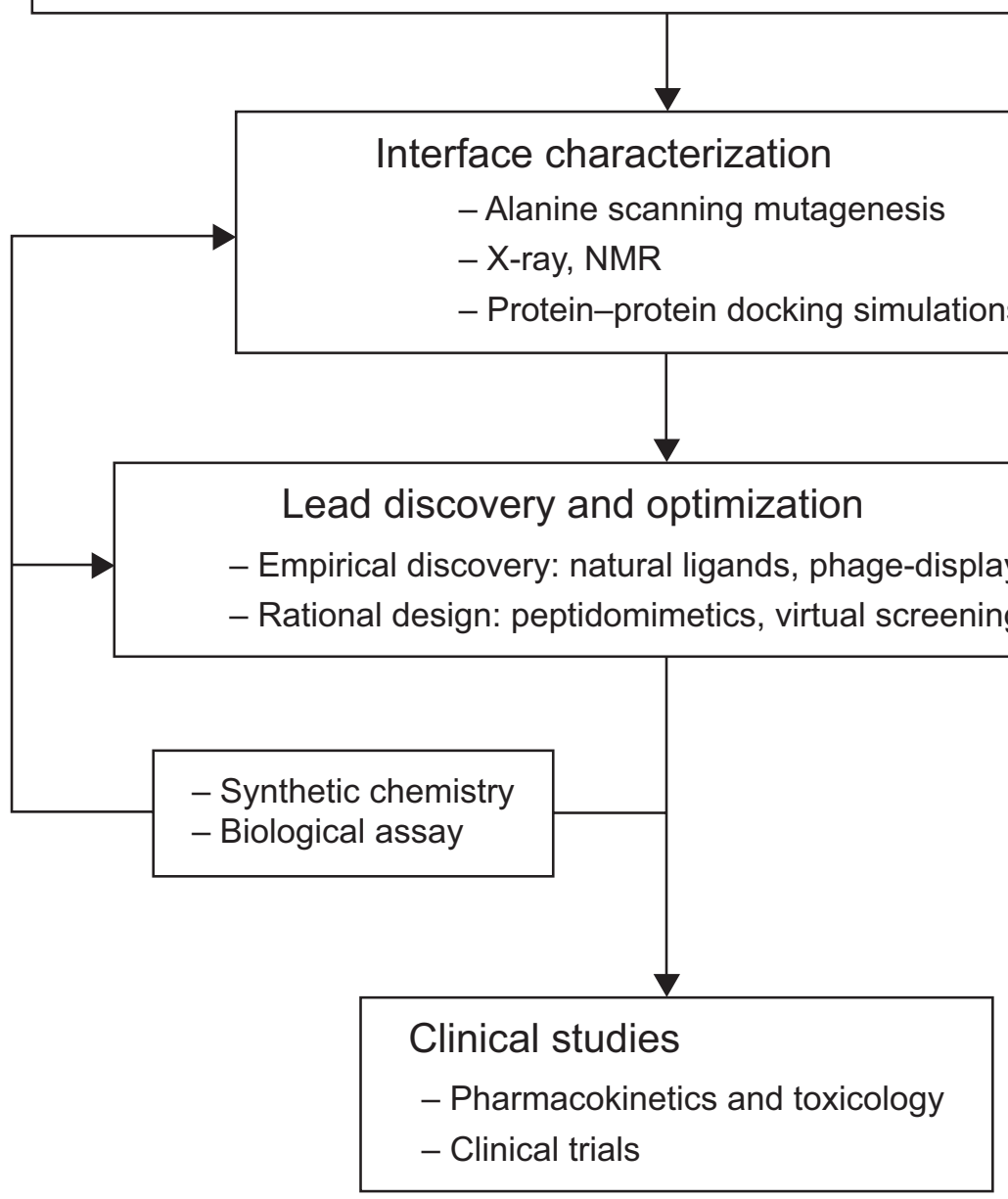

Figure I Flow-chart of the drug discovery process targeting protein-protein interactions.

BIND - Biomolecular Interaction Network Database; ${ }^{41}$ and private ones, such as PathCode ${ }^{\mathrm{TM}}$ from GPC-Biotech (http:// www.gpc-biotech.com/). This facilitated large-scale studies that aimed to map the network of PPI of complete living organisms. The first described maps were those of the hepatitis $\mathrm{C}$ virus; ${ }^{42}$ vaccinia virus, ${ }^{19}$ Saccharomyces cerevisiae,${ }^{43-45}$ Caenorhabditis elegans $;{ }^{46}$ or Helicobacter pylori. ${ }^{47}$ Other organisms followed, at different levels of completeness. ${ }^{48-51}$ The field is rapidly growing, and there are currently many web tools and data collections that are publicly available online (http://www.imbjena.de/jcb/ppi/jcb_ppi_databases.html).

\section{Target characterization: Structural information about the protein- protein complex and drugability of the targeted PPI Location of the interface}

Mutational studies

Alanine-scanning mutagenesis ${ }^{3}$ combined with kinetic and thermodynamic measurements can be used to experimentally locate and characterize residues involved in PPI. A comprehensive database of energetic data for different 
protein-protein complexes, determined by alanine mutations (ASEdb), has been compiled and made publicly available (http://www.asedb.org/). ${ }^{52}$ This database is actively updated and it is commonly used both by experimentalists and by computational benchmark studies. ${ }^{53}$

\section{Computational prediction of protein-protein interfaces}

Can protein-protein interfaces be predicted from the structures of their components, or, in other words, are there specific chemical and physical characteristics on a protein-protein interface that we could use to predict protein-binding sites on a protein surface? The question is far from being solved. Pioneer studies found that PPI sites have specific structural characteristics that differentiate them from other areas of the protein surface. ${ }^{54-60}$ However, when oligomeric proteins were excluded from the analysis, the results showed that chemical composition of protein-protein interfaces does not seem to differ greatly from the rest of the solvent-accessible surface. ${ }^{61-63}$ Although chemical and physical complementarity between the interacting surfaces is essential for the recognition, it is difficult to find simple chemical or structural patterns on the surface of proteins that unequivocally define a protein recognition site.

Alternative strategies for prediction of protein-protein interaction sites have been recently developed (Zhou and Qin recently reviewed all the different approaches) ${ }^{64}$ Amongst them, methods based solely on sequence information have been reported. Receptor-binding domains were predicted by analyzing hydrophobicity distribution on protein sequences. ${ }^{65}$ Predictions were $59 \%-80 \%$ correct, depending on the database of protein interactions used. A neural network method that uses sequence profiles and solvent exposure of neighboring residues has been reported. ${ }^{66}$ The method was trained on 615 pairs of nonhomologous protein-protein complexes (homodimers and heterodimers), and was tested on different sets of bound and unbound proteins. In the case of unbound proteins, $70 \%$ of the predicted residues were correctly located at the protein-protein interfaces. More recently, Ofran and Rost developed a machine learning-based method called ISI (Interaction Sites Identified from Sequence) to identify interacting residues from protein sequences only. They combined predicted structural features with evolutionary information with no reference to the 3-D structure of the protein, and the strongest interface residue predictions reached $90 \%$ of accuracy in a cross experiment. ${ }^{67}$ Another method, based on a 3-D cluster analysis that evaluates residue conservation on a set of 35 protein families, can identify interfaces and functional residues. ${ }^{68}$

In addition to conservation, a combination of physical and empirical methods can give promising results for interface prediction, as in the Promate server (http://bioinfo.weizmann. ac.il/promate/). ${ }^{69}$ Considering energy-based approaches, the optimal docking area (ODA), a method based on the hypothesis that desolvation must play a central role during protein-protein binding, identifies continuous surface patches with optimal docking desolvation. This approach has been validated on 66 unbound non homologue protein structures involved in nonobligate protein-protein heterocomplexes and the ODA predicted regions were correct in $80 \%$ of the cases. ${ }^{70}$ The strategy has been applied to numerous cases of biological and therapeutic interest, with excellent predictive results. $^{71-74}$

\section{Structure determination of protein-protein complexes}

Once a target protein-protein interaction has been established, it is desirable to obtain the most detailed structural information at atomic resolution of the protein-protein complex by X-ray crystallography and/or NMR experimental techniques. During the last decades, a number of protein-protein complex structures of therapeutic interest have been solved and deposited in the PDB. ${ }^{4}$ However, solving the 3-D structure

Table I Computer approach to rational design of inhibitors/enhancers of protein-protein interactions

\section{Target identification}

I. Establish protein-protein interaction

\section{Target characterization}

2. Locate interface

3. Modeling protein-protein interaction

4. Finding putative small-molecule pockets

Lead discovery and optimization

5. Mimicking interface

6. Ligand docking
Correlated mRNA expression profiles; correlated elution; domain fusion patterns; automated literature mining

Surface analysis; hydrophobicity profiles; 3-D cluster analysis; residue conservation Rigid-body docking; energy minimization; side-chain refinement; flexible docking

Analysis of "hot-spots"; surface cavities

Energy minimization; graphic modelling

Flexible ligand docking; grid or explicit receptor representations; MC minimization 
of a protein-protein complex is still a long and difficult task, and the number of available coordinates of protein heterodimers is relatively small compared to the number of deposited individual protein structures. Therefore, there is a need for reliable computational tools that can predict protein-protein complex formation and help to theoretically analyze the phenomenon of association between proteins.

\section{Protein-protein docking prediction}

The so-called "protein docking" problem, that is the prediction of a protein-protein complex using only the coordinates of its separate subunits, is one of the major challenges in structural biology. Apart from the intrinsic academic interest in characterizing the determinants of molecular recognition, the scientific community increasingly requires computational tools to model the physiological interactions in which a protein is involved, once its 3-D structure has been solved. Given that the number of available 3-D structures of individual structures is significantly increasing with the upcoming structural genomics projects, ${ }^{75,76}$ and considering that solving the structure of a protein-protein complex is often qualitatively more difficult than solving its individual subunits, one can easily deduce the importance of computational prediction of protein-protein complexes for the proteomics era. For that reason, during the last 20 years, a variety of computational algorithms for automatic protein-protein docking have been developed. $5,77,78$

\section{Geometry-based protein-protein docking methods}

The analysis of protein-protein complex structures at atomic resolution gave the first glimpse of the determinants of protein docking. From the analysis of several protein-protein complex structures, the most obvious observation was that protein surfaces of interacting proteins at binding sites were often highly complementary (Figure 2). ${ }^{79,80}$ For that reason, early protein-protein docking algorithms were based on purely geometric criteria, aiming to maximize the shape complementarity between the two interacting molecules. ${ }^{7,80,81}$ Conformational search of the best fit was performed on the rigid-body (ie, fixed backbone and side-chain conformation) representation of molecules, by geometric methods such as 'sphere-matching' in the original DOCK algorithm. '

Many of the recently developed docking methods are still mainly based on the shape complementarity criterion and the rigid-body assumption. In these methods, efforts have been directed towards improvement of spatial conformational search by introduction of new minimization techniques. Simulated annealing by using Monte Carlo simulations facilitated the use of constraint-driven docking. ${ }^{82}$ One of the most important advances was the use of Fourier transformation techniques to rapidly evaluate all possible translations between the molecules in a given orientation in order to find the best geometry matching ${ }^{6}$ This method actually constitutes the basis of some of the most popular rigid-body docking approaches nowadays (eg, FTDOCK ${ }^{83}$ or ZDOCK). ${ }^{84,85}$ Other successful geometric-based docking methods are $\mathrm{Hex}^{86}$ and MolFit. ${ }^{6}$

In general, geometry-based rigid-body docking methods were able to find and score properly the correct solution when using the 3-D coordinates of the complexed subunits during simulations. ${ }^{6,8,87-90}$ However, when these methods were tested on real cases, using the 3-D coordinates of the uncomplexed subunits, the correct solution was often not properly discriminated from the false positives, or even was not found at all. ${ }^{8,88-90}$ Clearly, the geometry criterion was valid to rebuild a complex after separation of its bound subunits, given the additional induced shape complementarity of their

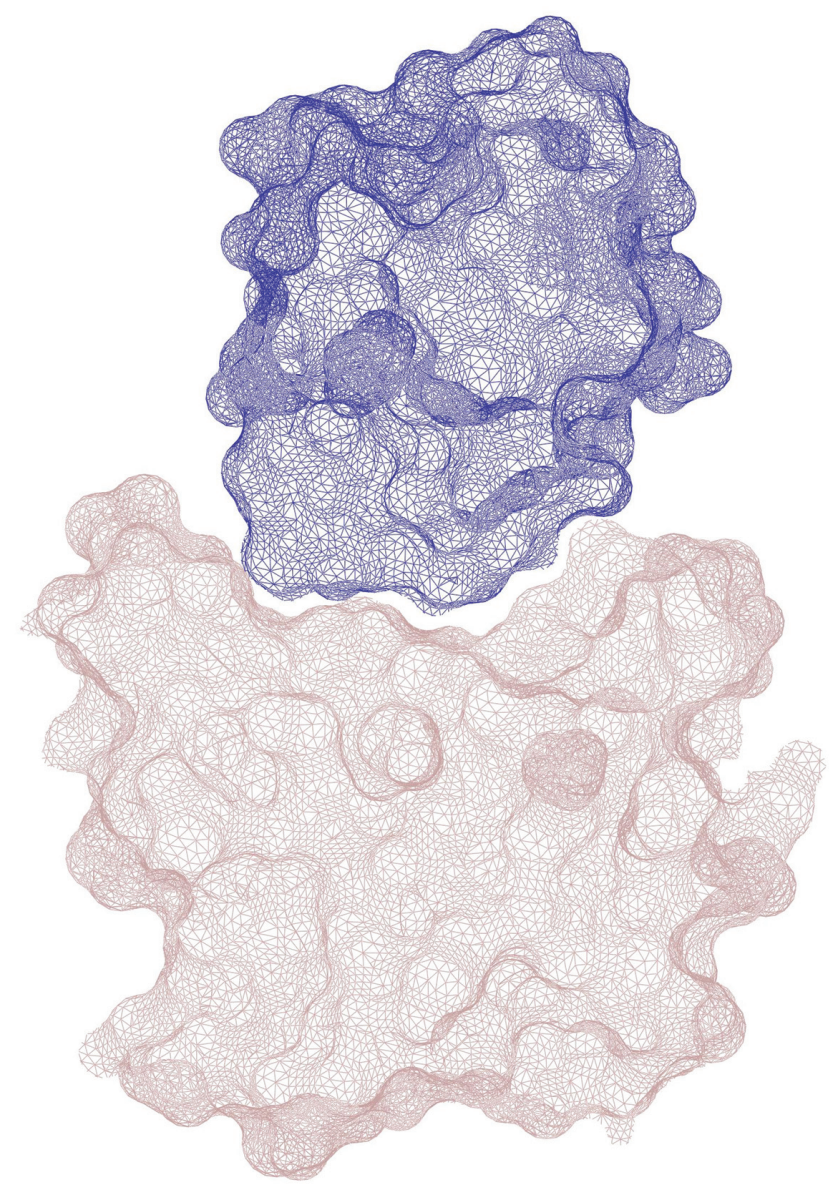

Figure 2 Shape complementarity at the interface of a protease-inhibitor complex (chymotrypsin/APPI; PDB code Ica0).

Abbreviation: PDB, Protein Data Bank. 
surfaces, but it was not able to correctly dock the unbound subunits, because their interacting surfaces are not always complementary enough. Thus, in order to model the induced fit that occur upon protein-protein association, it was necessary to overcome the rigid-body assumption, and to include in the scoring function other binding determinants than pure geometrical complementarity.

\section{Protein docking as a global energy minimization problem}

During formation of a protein-protein complex, the interacting interfaces of the approaching subunits fit each other to reach the native bound conformation. Since protein complexes are, in general, thermodynamically stable systems, the native bound conformation should represent the global minimum of the free energy, and therefore the docking problem can be reduced to finding this global minimum. From this point of view, geometry-based docking methods considered that the interaction energy was proportional to the contact area. Whereas this geometry-based approach can account reasonably well for the van der Waals interactions, it is clearly insufficient to describe other contributions to the interaction energy. Thus, different docking methods were developed to include other binding determinants, such as hydrogen bonding, ${ }^{91}$ electrostatic energy, ${ }^{92,93}$ solvation ${ }^{94}$ or hydrophobicity. ${ }^{95}$

At the same time, finding the global minimum of the free energy for a protein-protein association presented a conformational search challenge. As the rigid-body approach was insufficient to simulate the induced conformational fit upon binding, docking methods started to include strategies to mimic molecular flexibility during the optimization (Bonvin reviewed all the diverse strategies developed to deal with molecular flexibility upon binding during the docking process). ${ }^{10}$ The most practical strategy was the softening of the scoring function by imposing some limiting values to the steric energy terms, thus allowing some overlap of the interacting surfaces. ${ }^{83,96-100}$ This strategy overcame, to some extent, the difficulties stemming from the use of the unbound conformations of the interacting molecules. Explicit treatment of flexibility could lead to a more accurate description of the protein-protein complex formation phenomenon, but a full conformational search is currently impractical. However, since molecular association involves only small conformational changes in most of the known protein-protein complexes, ${ }^{63,101}$ computational requirements can be dramatically lowered by limiting conformational flexibility to interface side chains. ${ }^{102-108}$

The first docking method that considered continuous flexibility of interface side-chains during the global minimization process was based on internal coordinate mechanics (ICM). ${ }^{109-112}$ The ICM flexible docking procedure, successfully applied to the prediction of an antibody-lysozyme complex, ${ }^{113}$ was tested in a blind prediction contest. ${ }^{114}$ Although the ICM pseudo-Brownian method ${ }^{115}$ with subsequent global optimization ${ }^{116}$ of the interface side chain rotations lead to promising results, it was computationally too expensive to be tested on large databases of complexes. Therefore, an alternative two-step docking procedure (rigid body docking followed by ICM side-chain optimization) was proposed. ${ }^{9}$ The docking method used a fast soft interaction energy function pre-calculated on a grid, ${ }^{117}$ similar to the fast ligand docking procedures, ${ }^{118}$ which drastically increased the speed of the procedure. ${ }^{9}$ The scoring function used to evaluate the rigid-body docking poses was further optimized, for a better selection of docking solutions before the refinement step. ${ }^{119}$ The scoring function, composed by Coulombic electrostatics and ASA-based desolvation energy with atomic solvation parameters optimized for protein-protein docking, was later implemented in a docking protocol called pyDock, which was able to score docking sets generated by different docking methods. ${ }^{11}$ Other docking and/or scoring schemes that are based on energy description are Haddock, ${ }^{120}$ ClusPro/ SmoothDock, ${ }^{107,121}$ RosettaDock $^{108}$ and ATTRACT. ${ }^{122}$

Baker and colleagues improved side-chain modeling during docking significantly using a rapid and efficient method for sampling off-rotamer side-chains conformations by torsion space minimization. Their approach to include flexibility yielded better energetic discrimination between correct and incorrect docking models and a significant improvement in the quality of their predictions. ${ }^{123}$ Other approaches aim to include backbone flexibility by using conformational ensembles of the unbound subunits previously computed by Molecular Dynamics ${ }^{124,125}$ or by precalculating soft collective degrees of freedom by normal mode analysis (NMA) that are later used to include flexibility during docking. ${ }^{126}$ However, fully unrestricted molecular dynamics are too costly for routine application during docking. Nevertheless, there are important advances, as the use of steered molecular dynamics to give insights into the energy determinants and mechanism of TCR-pMHC association. ${ }^{127}$

\section{Benchmarking protein-protein docking methods}

To be used in practical applications, the protein-protein docking methods first have to be validated on a sufficiently large and diverse set of experimentally solved complex structures, ideally with individual subunit structures also experimentally determined. The problem is that there are 
not so many cases suitable for benchmarking. In one of the earliest benchmarking efforts, Norel and colleagues tested a rigid-body docking method on a set of complexes, starting from bound and unbound components. When the unbound subunits for both partners (in four different complexes) were used, the near-native solution had the lowest energy (eg, was identified as best docked) in only one case. ${ }^{8}$ FTDOCK docking method with refinement of binding side-chains was also benchmarked in a set of complexes (five cases when using unbound subunits). The near-native solution was ranked below 20 in all five cases, but it was predicted as the lowest energy solution in only one. ${ }^{105}$ BiGGER rigid-body method was later applied to 11 protein-protein complexes using the unbound subunits. The near-native solution was found among the docked conformations in eight out of the 11 cases, but was not ranked first in any of them. ${ }^{100}$ The ICM protein-protein docking ${ }^{9}$ was applied to a set of twenty-four protein-protein complexes (starting from the 3-D coordinates of bound and unbound subunits). When the unbound subunits were used, the near-native conformation was ranked below 20 in $85 \%$ of the complexes with no major backbone rearrangement upon binding (it was ranked 1 in $64 \%$ of the protease-inhibitor complexes). Recently, the laboratory of Weng has made an effort in providing suitable sets of cases for benchmarking of protein-protein docking methods. ${ }^{128-130}$ Nowadays, it is almost standard to provide success rates on these benchmarks. ${ }^{11,108,131}$

In 2001, an international protein-protein docking experiment called Critical Assessment of PRedicted Interactions (CAPRI; http://www.ebi.ac.uk/msd-srv/capri/capri.html) was launched, based on the CASP experiment model for single protein structural prediction. CAPRI is a blind test to evaluate the capacity of protein-protein docking algorithms to predict the binding-mode of two interacting proteins. This experiment allows direct comparison of different docking algorithms and permits also to follow the evolution of the performance of the most popular docking methods along time. ${ }^{132-135}$ Table 2 shows the results of all the CAPRI rounds that have been assessed so far, where the performance of the most active groups can be compared. In Figure 3 we can see three different examples of CAPRI results for the ICM and pyDock methods for targets 6, 14, and 25.

\section{Evaluate suitability for small-molecule binding (drugability)}

Computational methods to analyze the small-molecule drugability of a target protein-protein interface focus on the existence of 'hot-spots' and/or small pockets. Although the overall chemical composition of protein interfaces does not significantly differ from the rest of the solvent-accessible surface, ${ }^{61-63}$ structural analysis and experimental studies on protein-protein complexes underline the existence of 'hot-spots', eg, a few residues that confer most of the binding energy. ${ }^{136,137}$ These 'hot-spots' can be potential targets for small molecule drug discovery. ${ }^{138}$ Indeed, a specific interaction may be disrupted by targeting one or several of its hot spots. Consequently, low molecular weight compounds satisfying the requirements for orally deliverable drugs can be used to interfere with recognition sites in protein-protein interfaces that are usually above $800 \AA^{2}{ }^{139}$ Hot-spots can also be particularly helpful in difficult cases in which no small cavities are identified in flat protein-protein interfaces.

Experimental measurement of residue contributions to binding energy can be done by Alanine Scanning Mutagenesis combined with biophysical methods but this is a quite costly way to identify hot-spots. Therefore efforts have focused on computational prediction of these residues, and a variety of approaches have been reported based on residue conservation, ${ }^{140,141}$ machine-learning algorithm from protein sequence alone, ${ }^{142}$ hydrogen bonding, ${ }^{143}$ complete binding energy evaluation ${ }^{144-146}$ or propensity calculation from rigidbody docking. ${ }^{53}$ In Figure 4 we can see the high correlation between the hot-spot predictions from docking ${ }^{53}$ and the known experimental data for the IL4-IL4 receptor $\alpha$ chain.

The protein-protein interfaces most easily targeted with small molecule drugs typically contain a sufficiently deep surface pocket suitable for small molecule binding. ${ }^{147}$ Experimental and computational prediction of binding pockets on the surface of proteins has been successfully applied to rational drug design, ${ }^{14-153}$ and thus they can be one of the firstchoice computational tools to characterize a protein-protein interface in search of potential pockets.

\section{Discovery of inhibitors/promoters of PPI}

Given the role of PPI in regulating the majority of biological functions, PPI inhibition has long been one of the major goals in drug design. Empirical discovery of small compounds that can disrupt PPI has been traditionally difficult, ${ }^{154}$ and structure-based design of PPI inhibitors is currently limited to only a few successful cases. However, recent development of computational methods for protein-protein and protein-ligand docking is expected to facilitate the rational discovery of small compounds that can modify PPI. Several reviews of PPI modulation by small molecules have been published. ${ }^{155-157}$ Although the current review focuses on 


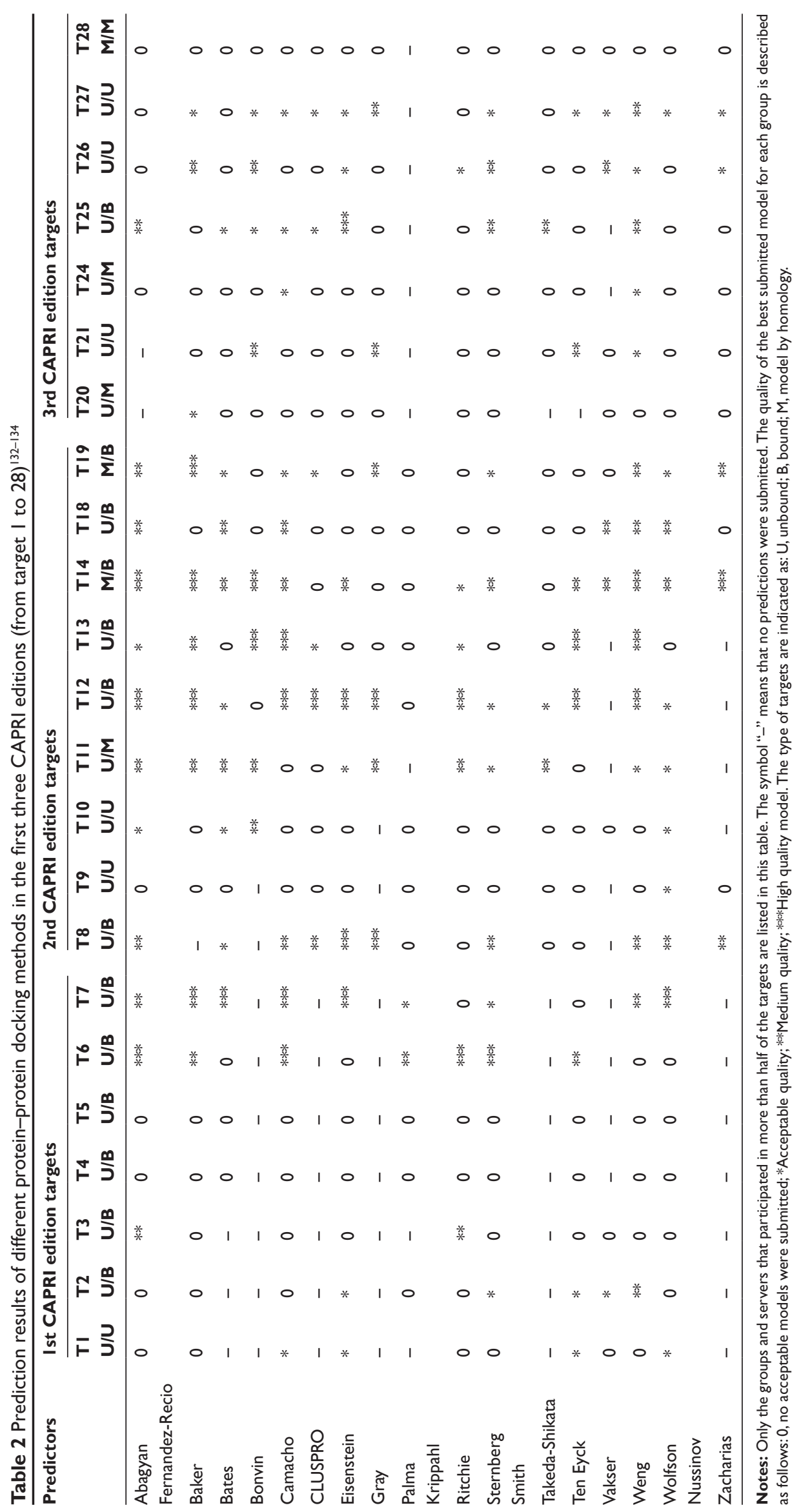


A

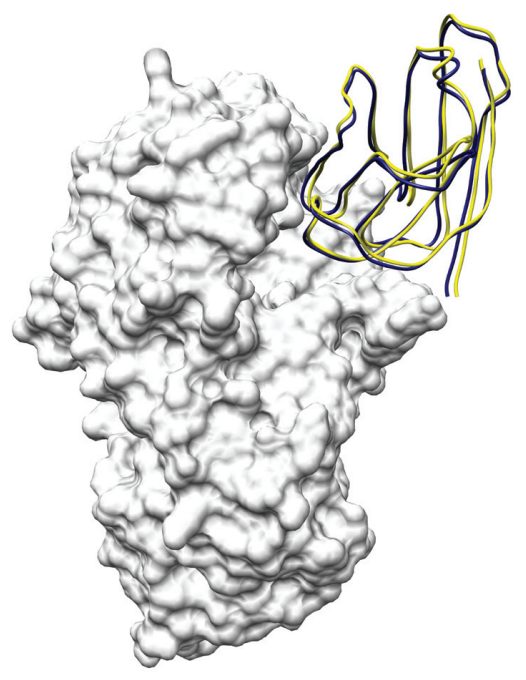

B

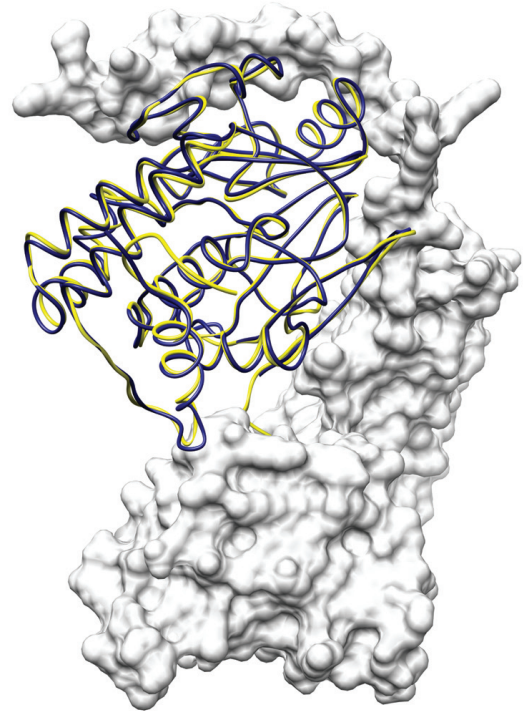

C

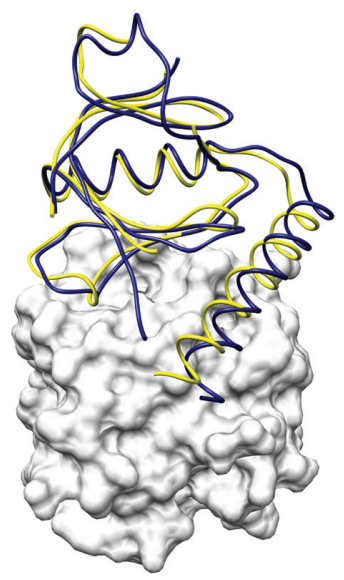

Figure 3 CAPRI Target examples: A) and B) are two high-quality models found with ICM and submitted for the CAPRI Targets 6 and I4 respectively, C) is a medium quality model found with pyDock submitted for the CAPRI Target 25. Complexes are shown as surface and ribbon. The correct position of the ligand is shown in yellow ribbon, the model is shown in navy blue ribbon.

Abbreviations: CAPRI, Critical Assessment of PRedicted interactions; ICM, internal coordinate mechanics.

computational approaches, we will overview here several examples of experimental discovery of compounds that can modify PPI, and we will give later more extended information on rational design of new PPI inhibitors based on structural data and computer simulations.

\section{Discovery of PPI agonists/antagonists: experimental approaches}

\section{Phage-display selection of peptides}

Phage display has been used to probe hot-spots as well as to identify novel peptide agonist/antagonists of PPI. ${ }^{158}$ For example, it has been used to select small peptides that can induce oligomerization in different cytokine receptors). ${ }^{157,159,160}$ Especially interesting was the case of the 20 residue cyclic peptide EMP-1, ${ }^{161}$ which induced dimerization of the EPO receptor. A small change in this sequence transformed its agonist character into antagonist. ${ }^{162}$ Cwirla and colleagues also identified small peptides that can induce receptor dimerization in thrombopoietin receptor (TPOR). ${ }^{163}$ An interesting drug discovery platform that used phage peptide libraries and HTS of small molecules based on the selected peptides was reported. ${ }^{164}$ This strategy was applied to the discovery of agonist/antagonist peptides and small molecules in the insulin-like growth factor-1 (IGF-1)/IGF-1 receptor system, and has been also used to identify a binding epitope and potential protein-protein interaction partners of a given protein, by searching in the sequence databases. In the case of the insulin receptor, both agonists and antagonists have been discovered using phage display. This technology even allowed a better understanding of the receptor molecular architecture with identification of critical regions required for its biological activity. ${ }^{165}$ Potent antagonists called "zeta" peptides of the high-affinity immunoglobulin E (IgE) receptor have also been identified and prevent histamine release from cultured cells. Moreover, these peptides that acts as competitive IgE inhibitors can be used for further design of IgE inhibitors. ${ }^{166}$

\section{Discovery and optimization of natural ligands}

Natural products didemnaketals A and B were used to synthesize simplified analogs that inhibited HIV protease homodimerization. ${ }^{167}$ Chalcone derivatives, with known anticancer properties, were recently described to inhibit interactions between the human oncoprotein MDM2 and p53 tumor suppressor protein. ${ }^{168,169}$ Cyclodextrin dimers (CD) that disrupt PPI by targeting hydrophobic patches have been also reported. ${ }^{170}$ Interestingly, small molecules and peptides can also induce an unwanted stabilization of a protein-protein complex. This is the case of Brefeldin A, a small hydrophobic compound produced by toxic fungi that has dramatic effects on mammalian cells. It has been proposed that brefeldin A works as an uncompetitive inhibitor stabilizing a transient "dead-end" complex between Arf exchange factor and Sec7 domain of Gea1, Gea2 and Sec7 proteins. ${ }^{171}$ On the other 
side, a large number of natural compounds have been known to target the tubulin-tubulin interaction to stop cancer cells division, and some new molecules are currently used in clinical trial for cancer therapy. ${ }^{172}$

\section{High-throughput screening of small molecules}

High-throughput screening (HTS) methods have been used to discover small compounds capable of inhibiting PPI, especially when no structural information is available about the target proteins. ${ }^{173}$ In general, HTS is less successful in identifying PPI inhibitors than in identifying any other type of inhibitor: PPI are extended over a big interface

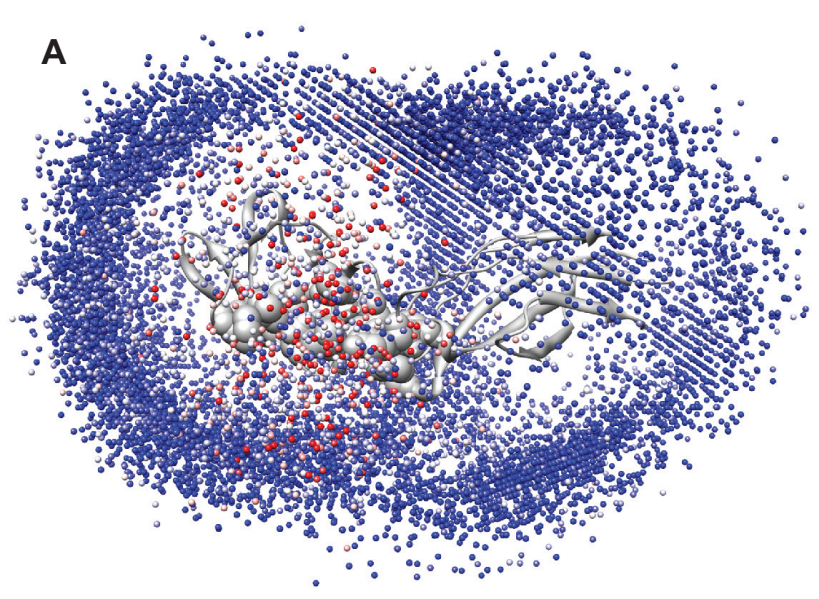

B

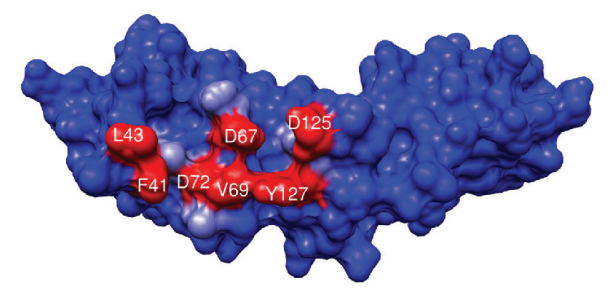

C

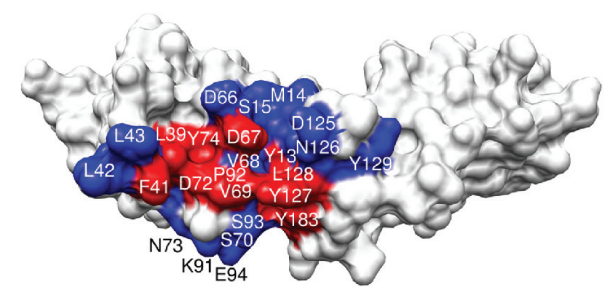

Figure 4 Normalized interface propensity (NIP) calculation from rigid-body docking for the prediction of hot-spots on the complex between the IL-4 and its IL4 receptor $\alpha$ chain (complex PDB code liar). A) The IL-4 receptor $\alpha$ chain is represented as grey ribbon, and the dots represent the center of coordinates of each of the 12000 rigid-body docking solutions poses colored according to the pyDock scoring function on a scale from red to blue: lowest energy values are shown in red. B) The IL-4 receptor $\alpha$ chain surface is colored according to the NIP value of each residue obtained from the 100 lowest-energy docking solutions. The predicted hot-spots corresponding to the highest NIP values (cutoff $>0.4$ ) are shown in red. C) The IL-4 receptor $\alpha$ chain surface is colored according to the available experimental data. The residues shown in red are the ones experimentally known as hot-spot (ie, they contribute more than I kcal. mol-I to the binding energy). The residues shown in blue are experimentally known as nonhot-spot, and the residues in white have no available experimental data. Abbreviations: IL, interleukin; PDB, Protein Data Bank. (average binding energy per unit area: $\left.9 \mathrm{cal} / \mathrm{mol} \cdot \AA^{2}\right)^{154}$ and are difficult to target with a small site-specific drug (average binding energy per unit area: $31 \mathrm{cal} / \mathrm{mol} \cdot \AA^{2}$ ). Tian and colleagues used a high-throughput, cell-based screen to detect small compounds that activated the murine granulocyte-colony-stimulating factor (G-CSF) receptor. ${ }^{174}$ They found a small molecule (SB 247464;Figure 5a) that replaced the natural protein ligand G-CSF in its role of inducing oligomerization of G-CSF receptor chains, thus triggering the corresponding signal transduction pathways. Later, it was shown that SB 247464 could dimerize the G-CSF receptor in a different manner than G-CSF, through a Zinc mediated interaction. It also appeared that SB 247464 and G-CSF bound to different sites on the receptor, given that the small compound was unable to compete with G-CSF receptor natural ligand to initiate the dimerization. ${ }^{175}$ This constituted one of the first examples of a synthetic small molecule capable of dimerizing cell surface receptors.

Similarly, Kimura and colleagues screened many compounds capable of inhibiting the binding of thrombopoietin (TPO) to the cell surface receptor c-Mpl, necessary for triggering megakaryopoiesis and platelet production cascades after receptor oligomerization. They found two small inhibitor compounds, TM4 and TM41 (Figure 5b), which were able to replace the natural TPO in its role of inducing c-Mpl oligomerization. ${ }^{176}$

HTS techniques have also been used to find a molecule that inhibited interaction between EPO and EPO receptor (Figure 5c). A multimeric form of this molecule was also synthesized and shown to induce dimerization in the EPO receptor, thus mimicking the physiological role of EPO. ${ }^{177,178}$ A cell-based screening assay was also used to select a molecule $(\mathrm{L}-783,281)$ that activated insulin receptor (Figure 5d). The mechanism proposed was that L-783,281 bound the tyrosine kinase domain of the insulin receptor, altering its conformation and leading to its activation. ${ }^{179}$

Combinatorial piperazinone libraries have been used to find compounds that disrupt the interaction between the transcription factor LEF-1 and the protein $\beta$-catenin, which accumulates in a majority of colorectal tumors. ${ }^{180}$ The complex formed between the Tcf4 transcription factor and the $\beta$-catenin, also involved in colorectal tumors, has been investigated by screening several thousand of natural compounds, among which six inhibitors in the low micromolar range were found. ${ }^{181}$ A combinatorial chemical library based on a pyrimidineimidazole core has been designed to find inhibitors of the inducible nitric oxide synthase (iNOS). This enzyme that generates NO from L-arginine is involved 
A<smiles>c1ccc(C23NC(=Nc4nc5ccccc5[nH]4)NC2(c2cccc(N=C4NC5(N4)NC(=Nc4nc6ccccc6[nH]4)N5)n2)N3)nc1</smiles>

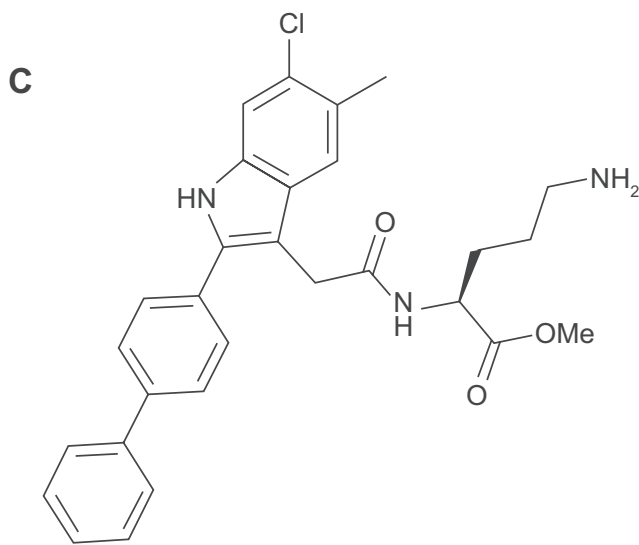

\section{B}

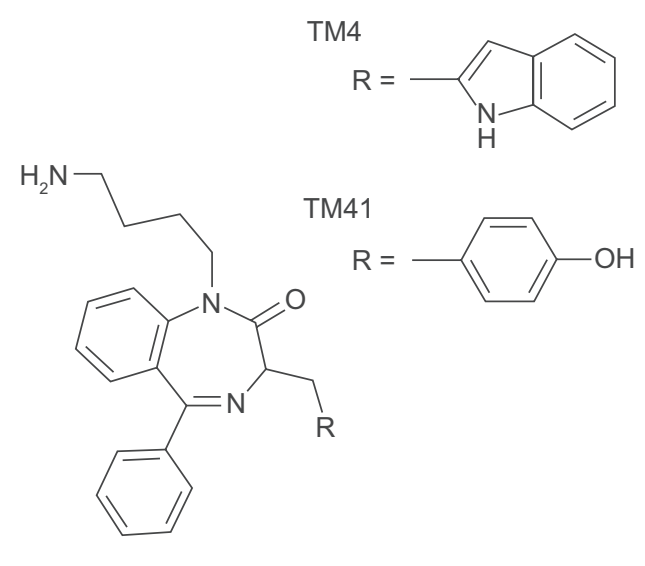

D

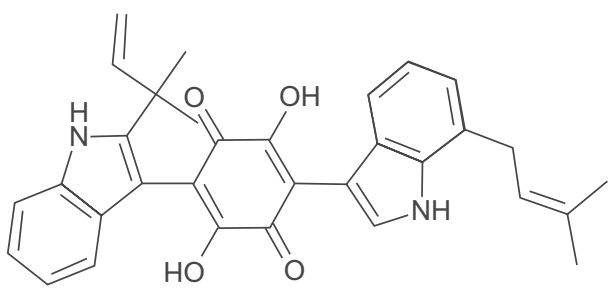

Figure 5 A) Molecule SB 247464; B) Molecules TM4 and TM4I; C) Inhibitor of EPO-EPOR interaction; D) Molecule L-783, 28I.

in tissue damage during inflammation and is fully active as a dimer. By screening, Devlin and colleagues found a class of potent, selective and cell permeable iNOS inhibitors capable of preventing its dimerization. ${ }^{182,183}$

The oncoprotein c-Myc, over expressed in many human tumors (lung, colon, Burkitt's lymphoma), requires binding to its activation partner Max in order to interact with DNA and achieve its transcription factor function. Because of its potential therapeutic applications, this interaction was studied by HTS and allowed the discovery of two potent and selective dimerization inhibitors: Mycro1 and Micro2, both in the low micromolar range. ${ }^{184}$ The complex formed between TNF-alpha and its receptor TNFRc1 were known to be inhibited by antibodies and soluble receptors, but no potent small molecule was reported until Muckelbauer and colleagues performed screening on this system and discovered two inhibiting small-molecule compounds acting through covalent modification of the receptor via a photochemical reaction. ${ }^{185}$ HTS has also been used to discover two classes of competitive antagonists for the interaction B7.1/CD28, involved into the T-cell response augmentation, with potential therapeutic applications in immunotherapy after transplantation or autoimmune diseases. ${ }^{186}$ More recently, a Rac activation-specific inhibitor of the Rac1-GEF interaction that could be useful for therapeutic targeting at Rac deregulation has also been found in this way. ${ }^{187}$

\section{Fragment-based lead discovery}

Fragment assembly is a recent approach developed to help finding or optimizing leads during the drug discovery process. A set of small fragments are screened against the protein of interest and the binders are then combined to form small-molecule compounds, which significantly increases the search process efficiency. Indeed, the chances of finding a hit are higher than in conventional HTS. ${ }^{188}$ Hajduk and Greer analyzed the impact of fragment-based methods in drug design over the last decade, 
showing a list of all the targets studied through fragment-based approach that lead to potent inhibitors discovery. ${ }^{189}$ For example, a potent inhibitor of the anti apoptotic Bcl-2 family proteins (Blc-2, Bcl-XL and Bcl-w) was discovered using NMR-based screening of small fragments combined with structure-based drug design. The molecule, called ABT-737 showed a strong capacity to reduce regression of solid tumors in mice. ${ }^{190}$ Tethering is a fragment-based method relying on the reversible formation of a disulfide bridge between the target protein and the fragment. In this way, the search region is controlled by the introduction, by site-directed mutagenesis, of a cysteine residue near the site of interest of the target protein, which in addition facilitates the computational analysis of potential binding modes. ${ }^{191}$ With this approach, a known inhibitor (in the millimolar affinity range) of the interaction between IL-2 and its receptor got its affinity significantly increased. The X-ray structure of the previously known IL-2/inhibitor complex revealed an adaptive IL-2 interface, in which a small molecule binding site was created. The application of the tethering approach resulted in a clear improvement of the original molecule to the nanomolar affinity range. ${ }^{192,193}$

\section{Rational design of PPI inhibitors: computational approaches}

In principle, the problem of PPI inhibition seems to be just a particular case of the broader drug design field, but a deeper analysis shows intrinsic characteristics that make it a distinct field. While drug design, in general, is focused on the discovery of small compounds that can bind into natural ligand-binding pockets or active centers of proteins of therapeutic interest, ${ }^{194}$ inhibition of PPI requires identification of small compounds capable of disrupting a large and highly complementary interaction surface between two proteins (Figure 6). The absence of well defined, deep pockets in protein-protein interfaces, and the large number of intermolecular contacts arising from their high geometrical and chemical complementarity makes the problem especially difficult. Nevertheless, several methods for rational design of PPI inhibitors have been recently applied to particular cases with some success. The constant increase in computational power and the development of new efficient and accurate computer tools for drug design are starting to yield promising results in this very challenging area.

\section{Mimicking protein-protein interfaces:}

from peptides to small molecules

Antibodies capable of blocking or enhancing PPI have been reported, for example a monoclonal antibody that can induce homodimerization of erythropoietin receptor and triggers cell proliferation cascades, ${ }^{195}$ or a monoclonal antibody that may block critical PPI of HIV-1 integrase. ${ }^{196}$ The use of antibodies in cancer therapy is highly promising. ${ }^{197}$
A

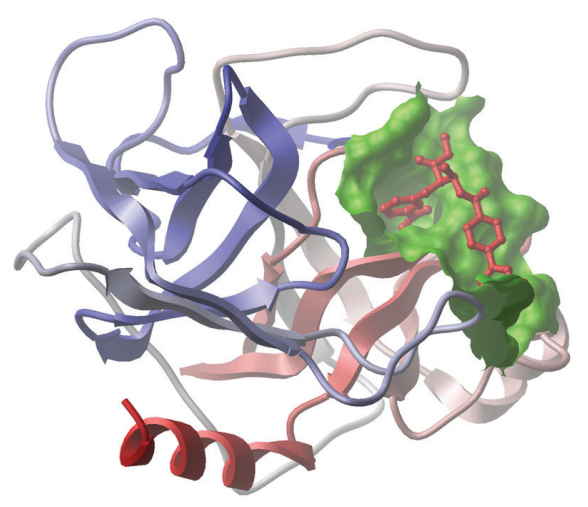

B

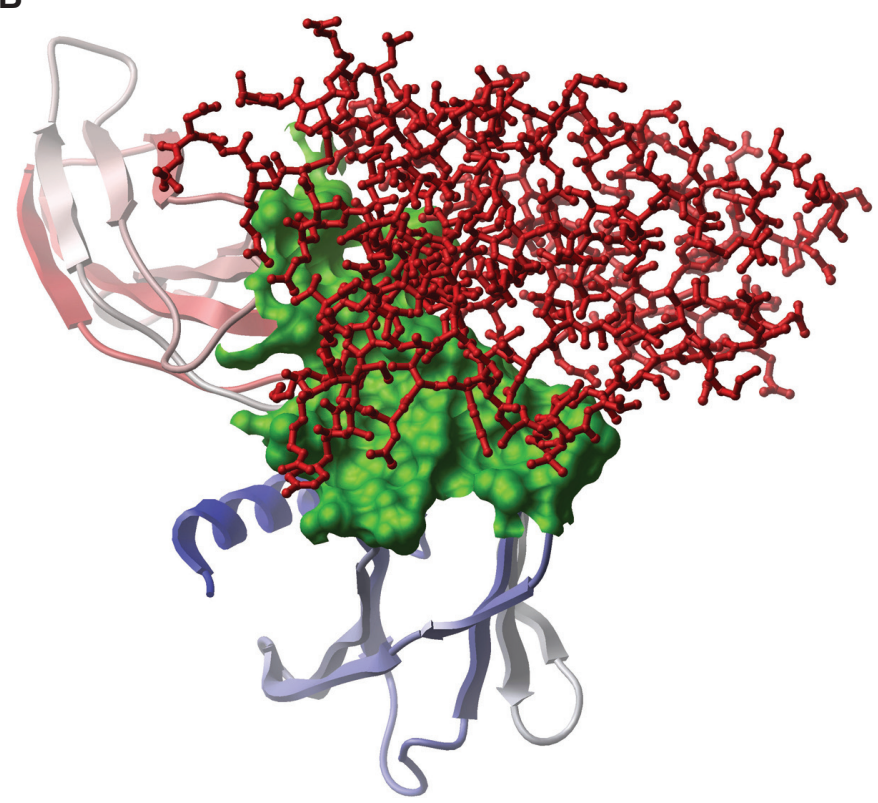

Figure 6 An example of a protein-small molecule interface A: complex trypsin/RPR I285I5 inhibitor (PDB IfOu) compared to a protein-protein interface B: complex EPO receptor/EPO (PDB leer). The protein-small molecule interface $\mathbf{A}$ ), with fewer inter-atomic contacts, is noticeably smaller and deeper than the shallow, large protein-protein interface B). The molecules are shown in the same scale.

Abbreviation: PDB, Protein Data Bank. 
However, clinical use of antibodies presents in practice numerous problems (high cost for large-scale production, drug delivery, immunoreactivity, etc.). ${ }^{198}$ Fortunately, there are some reported examples of design of small molecule inhibitors that mimic an antibody binding function. ${ }^{199,200}$ Based on this strategy, Chrunyk and colleagues proposed to design small compounds to mimic the binding of antibodies that can act as blocking agents of PPI. ${ }^{201}$ They selected a monoclonal antibody to block interaction between proteins IL-1 $\beta$ and IL-1R and they found that a simpler single chain antibody retained the same blocking capacity, leaving the door open for future design of PPI inhibitors. Similarly, a calyx[4]arene scaffold with pendant cyclic peptide units was designed as a mimetic of antibody Fab fragments, and was shown to bind cytochrome $\mathrm{c}$ in the same region of the protein as its natural protein partners (cytochrome oxidase, cytochrome c peroxidase). ${ }^{202}$

Structure-based design of peptides that mimic structural elements of a protein-protein interface ${ }^{203,205}$ has been widely applied for the inhibition of PPI. ${ }^{155,206,207}$ Some examples of the so-called "interface peptide" strategy include: peptide inhibitors of different adhesive proteins such as $\alpha$-actinin and vinculin; ${ }^{208,209}$ short peptides that inhibit homodimerization of HIV-1 protease; ${ }^{210,211}$ a stabilized helicoidal peptide that inhibits a domain-domain interaction between the $\mathrm{N}$-terminal and C-terminal domains of the HIV-1 envelope glycoprotein gp41, disabling thus membrane fusion between the virus and target cells; ${ }^{212}$ synthetic peptides that inhibit homo-dimerization of thymidylate synthase (TS); ${ }^{213}$ a $\beta$-sheet peptide that inhibits dimerization of the small E47 transcription factor; ${ }^{214}$ a synthetic cyclic heptapeptide that inhibits interaction between CD4 and major histocompatibility complex (MHC) class II proteins; ${ }^{215,216}$ synthetic peptides that block interaction between CD8 and MHC class I proteins ${ }^{217}$ synthetic peptides that inhibit dimerization of the HIV reverse transcriptase; ${ }^{218-220}$ inhibition of HIV-1 protease homodimerization by a small tethered peptide; ${ }^{221}$ inhibition of the herpes simplex virus ribonucleotide reductase dimerization by a small hexapeptide resulting in a stronger effect on replication than the Acyclovir, ${ }^{222}$ and peptides targeting SH3-mediated PPI. ${ }^{223}$ Ferrer and colleagues used a combinatorial chemical library to find elements that, when covalently attached to a peptide derived from the outer layer $\alpha$-helix, could inhibit gp-41-mediated HIV-1 cell entry. ${ }^{224}$ Based on the X-ray structure of the inhibitor in complex with the HIV-1 gp41 trimeric core, ${ }^{225}$ they showed that blocking a small cavity was sufficient to inhibit the interaction between the core coiled-coil and the outer-layer $\alpha$-helix of gp41. However, the small molecule alone had no inhibitory activity, although it increased the potency of the 30-mer mimetic peptide.

The discovery of peptide, peptidomimetic and small molecule inhibitors of the association between integrin $\alpha 4 \beta 1$ (VLA-4) and the endothelial surface protein vascular cell adhesion molecule (VCAM) was reported. ${ }^{226-228}$ A review of structure-based design of phosphopeptides and small molecule inhibitors of Grb2-SH2 mediated PPI has been published. ${ }^{229} \mathrm{~A}$ peptide sequestering the antiapoptotic protein $\mathrm{Bcl}-2$ has been optimized to increase its "mimicking" capability with respect to the $\mathrm{BH} 3$ domain of BID (a pro-apoptotic BH3-only protein) by hydrocarbon stapling. The resulting BH3 domain alpha-helix is more rigid, protease-resistant, cell permeable and binds with increased affinity to Bcl-2. This inhibitor suppresses the growth of human leukemia cells in vitro, and it prolongs the survival of leukemic mice in vivo. ${ }^{230}$ Furet and colleagues applied a structure-based approach to improve 1700-fold the binding affinity towards hdm 2 of their initial peptide derived from the N-terminal domain of $\mathrm{p} 53$. They discovered potent antagonists of the p53-hdm2 interaction, which constitutes an attractive approach for cancer therapy. ${ }^{231}$ Several "two turns" structural mimics of the myosin light chain kinase present functional homology in its high affinity binding to calmodulin, and are able to inhibit the calmodulin activation of PDE enzyme in the nanomolar range. ${ }^{232}$

Although design of peptide molecules that mimic protein-protein interfaces or antibody binding is an interesting approach, the ultimate goal is the design of small nonpeptidic PPI inhibitors (generally with MW < 500), more desirable for therapeutic use than peptides or peptidomimetics. Tilley and colleagues designed a series of acylphenylalanine derivatives intended to mimic the proposed binding region of interleukin-2 (IL-2) to the $\alpha$ receptor subunit (IL-2R $\alpha$ ), based on a combination of structural information of IL-2 (by X-ray and NMR data) and site-directed mutagenesis. Structureactivity studies led to a small compound with an $\mathrm{IC}_{50} \mu \mathrm{M} .^{233}$ Similarly, Sarabu and colleagues designed a series of small molecule antagonists for the interaction between interleukin-1 alpha protein (IL-1 $\alpha$ ) and the Type I receptor, with potential interest to treat inflammation related diseases. ${ }^{234}$ The design was based on the 3-D structure of the proposed binding epitope for IL-1 $\beta$ (derived from the X-ray structures of IL-1 ligands and site-directed mutagenesis data).

Nonpeptidic inhibitors of the interaction between fibrinogen and GPIIb-IIIa integrin, association that is essential for platelet aggregation, have been designed based on the tripeptide sequence Arg-Gly-Asp (RGD). ${ }^{235,236}$ Several 
of these molecules (xemilofiban, orbofiban, sibrafiban, and lotrafiban; Figure 7) have progressed until phase III clinical trials but unfortunately they did not reach the market due to both a lack of efficacy ${ }^{237}$ and safety concerns. Other nonpeptidic RGD mimics have been designed based on spirocyclic structures. ${ }^{238,239}$

Based on the structure of the complex between the B domain $(\mathrm{Fb})$ of Staphylococcus aureus protein $\mathrm{A}(\mathrm{SpA})$ and the Fc fragment of IgG (Figure 8a), ${ }^{240} \mathrm{Li}$ and colleagues used computer-aided molecular modeling to design a molecule mimetic for protein A (Figure 8b) that is an effective competitive inhibitor for its interaction with IgG (Figure 8c). ${ }^{241}$

Another interesting strategy for PPI inhibition is the use of transition metal complexes to target distinctive patterns of histidine residues on the surface of a protein. ${ }^{242} \mathrm{~A}$ review of rational design of PPI inhibitors involving the TNF family cytokines has been published. ${ }^{243} \mathrm{~A}$ different area of therapeutic interest involving PPI is the formation of amyloid fibrils. Klabunde and colleagues discovered small compounds that can inhibit transthyretin (TTR) fibril formation by stabilizing the native tetrameric conformation of TTR. ${ }^{244}$ They used a structure-based drug design approach based on the crystal structures of TTR complexed with known amyloid fibril inhibitors. Their work represents a good example of modulating PPI by enhancing stability of the complexed conformations avoiding unbound conformations that lead to disease.

Protein interfaces can be artificially re-engineered. A particularly difficult task is to break strong PPI in which two monomers are interlocked through extensive interactions and side-chain mutations are insufficient. Borchert and colleagues re-engineered the backbone of loop3 at the interface between two triose-phosphate isomerase monomers, which led to predicted monomeric structures. ${ }^{245,246}$ Engineered protein-protein interfaces, artificially disrupted after the introduction of cavities by using alanine-scanning mutagenesis, can be restored with small molecules bound to the cavity, thus generating artificial small molecule switches for PPI. ${ }^{247}$ Although rational design of the protein-protein interfaces themselves has limited therapeutic interest, it could be useful to understand the physicochemical basis of PPI modulation, and also to generate manipulated organisms in biotechnology that functionally respond to specific molecules.

\section{Computer-aided design: virtual screening and docking simulations}

Computational simulations is increasingly facilitating rational design of small molecules that can inhibit or stimulate the biological activity of specific proteins, mostly by targeting a clearly defined binding pocket. ${ }^{194,248}$ However, so far very few inhibitors of PPI have been designed using computer simulations (see recent reviews focused on virtual screening for the identification of inhibitors of PPI). ${ }^{249-251}$

Computational approaches have been successfully applied to optimize peptidic ligands in several systems. Zeng and colleagues used a combinatorial algorithm ${ }^{252}$ based on the MCSS approach ${ }^{149}$ for the optimization of

B

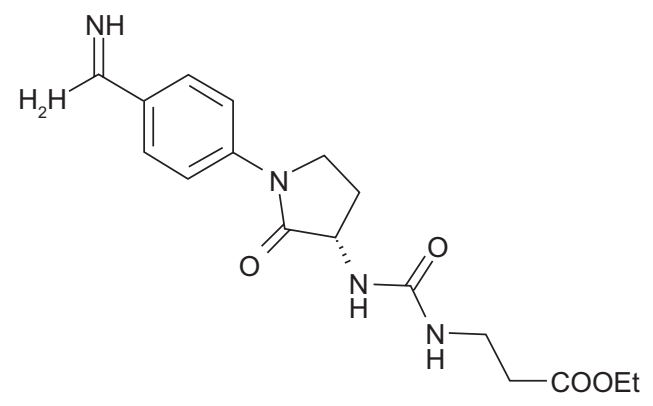

D<smiles>CN1Cc2cc(C(=O)N3CCC(C4CCNCC4)CC3)ccc2N[C@H](CC(=O)O)C1=O</smiles>

Figure 7 Some small molecule antagonists of GPIlb-IIla; A) xemilofiban; B) orbofiban; C) sibrafiban; D) lotrafiban. 


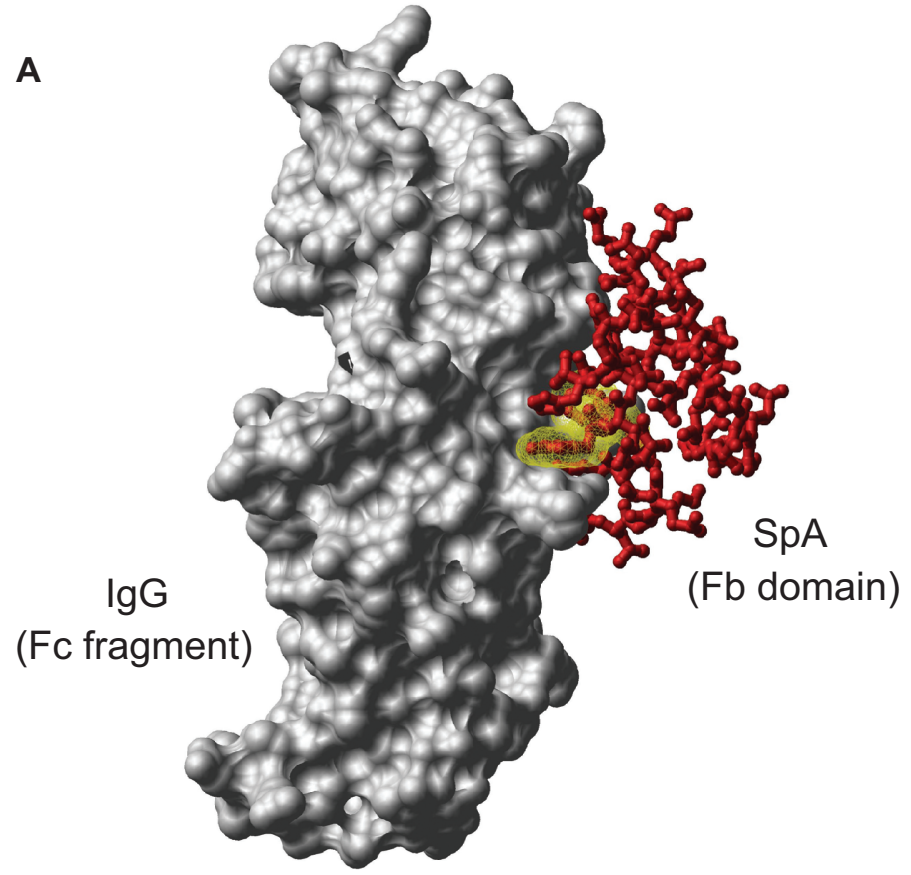

B<smiles>NCCNc1nc(NCCc2ccc(O)cc2)nc(Nc2ccccc2)n1</smiles>

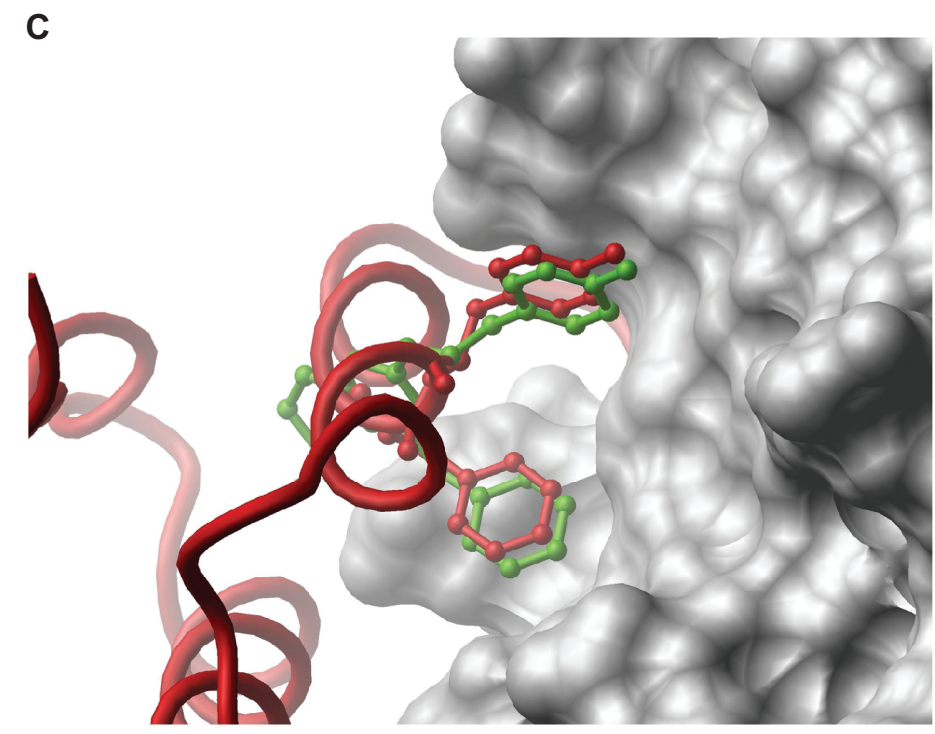

Figure 8 A) Structure of the complex (PDB: Ifc2) between the Staphylococcus aureus Protein A Fb domain (solid surface) and the lgG Fc fragment (red); Side-chains of binding residues Phel32 and Tyr I33 of Protein A are shown in yellow; B) Small molecule competitive inhibitor ApA; C) Model of the interaction between IgG (solid surface) and inhibitor ApA (in green), superimposed on the binding residues Phel 32 and Tyr 33 of the complexed Protein A structure (red ribbon).

Abbreviation: PDB, Protein Data Bank.

peptides that inhibit the association between Ras and Raf, proteins involved in signal transduction pathways and in many oncogenic events..$^{253}$ Furet and colleagues ${ }^{254-256}$ optimized the inhibition properties of the phospho-tripeptide pTyr-Ile-Asn by molecular modeling and found a derivative capable of blocking the interaction between the activated tyrosine kinase growth factor receptors (TKGFR) and the $\mathrm{SH} 2$ domain of Grb2 (see a review of SH2 domain and drug discovery) ${ }^{257}$ Proline-rich peptides targeting SH3 domains were computationally optimized using the programs GRID ${ }^{117}$ and LUDI, ${ }^{258}$ obtaining an increment of 100-fold in affinity and 1000-fold in selectivity. 
Fewer computational methods have been developed for rational design of small nonpeptidic compounds to inhibit PPI. Li and colleagues applied computer screening to select small nonpeptidic organic molecules that can inhibit interaction between CD4 and MHC class II proteins. ${ }^{147}$ Based on the X-ray structure of the human CD4 D1 domain, ${ }^{259}$ and using a combination of theoretical prediction and synthetic peptide experiments, the authors identified a surface pocket potentially involved in functional binding to MHC class II (Figure 9a). The identification of such a surface pocket was critical for the success of the strategy. The authors used the computer program DOCK $3.5^{260}$ to screen the available chemicals directory (ACD) (Molecular Design Limited, San Leandro, CA, USA), that included around 150,000 commercially available small organic compounds, in search for possible ligands to that particular pocket. They finally selected four compounds with significant inhibitory activity (45\%-75\% at $100 \mu \mathrm{M}$ ) for the CD4-MHC class II interaction (Figure 9b).

A novel class of low molecular weight hydantoins, which inhibits the interaction between the lymphocyte function-associated antigen-1 (LFA-1) and the intercellular adhesion molecule (ICAM-1) by allosteric regulation, ${ }^{262}$ represented an alternative example of PPI regulation. Based on an integrated immunochemical, chemical, and molecular modeling approach, the following allosteric inhibition mechanism was proposed: the hydantoins bind to LFA-1 and drive the equilibrium between active and inactive states of LFA-1 towards the conformation that is unable to interact with ICAM-1. ${ }^{263}$ Bushweller and colleagues found four new inhibitors that effectively blocked the interaction between Runx 1 and CBF $\beta$ with low micromolar affinity, amongst 35 potential candidates selected by virtual screening. An NMR spectroscopy screening study showed later that none of these compounds were directly bound to the protein-protein interface, which suggested the existence of allosteric effects in the inhibition. ${ }^{264}$

Virtual screening has been used to identify 13 nonpeptide drug-like inhibitors targeting the p56Lck SH2-domain from an initial screening of 25,000 compounds. ${ }^{265}$ Amongst the 13 inhibitors, two were identified as potential lead compounds for further development. ${ }^{266}$ In another example, virtual screening of 640,000 compounds was performed with DOCK4.0.1 in order to target the interaction between S100B and $\mathrm{p} 53$, which lead to the discovery of seven inhibitors in the micromolar range. Five of these compounds inhibited growth of primary malignant melanoma cells and are currently being optimized to find higher affinity inhibitors for potential applications in cancer therapy. ${ }^{267}$ The extracellular kinases ERK1/2, which play an important role in a signaling pathway involved in proliferation, are believed to be interesting targets to arrest cell proliferation in cancer. Only two proteins are known to turn on ERK1/2 kinases,
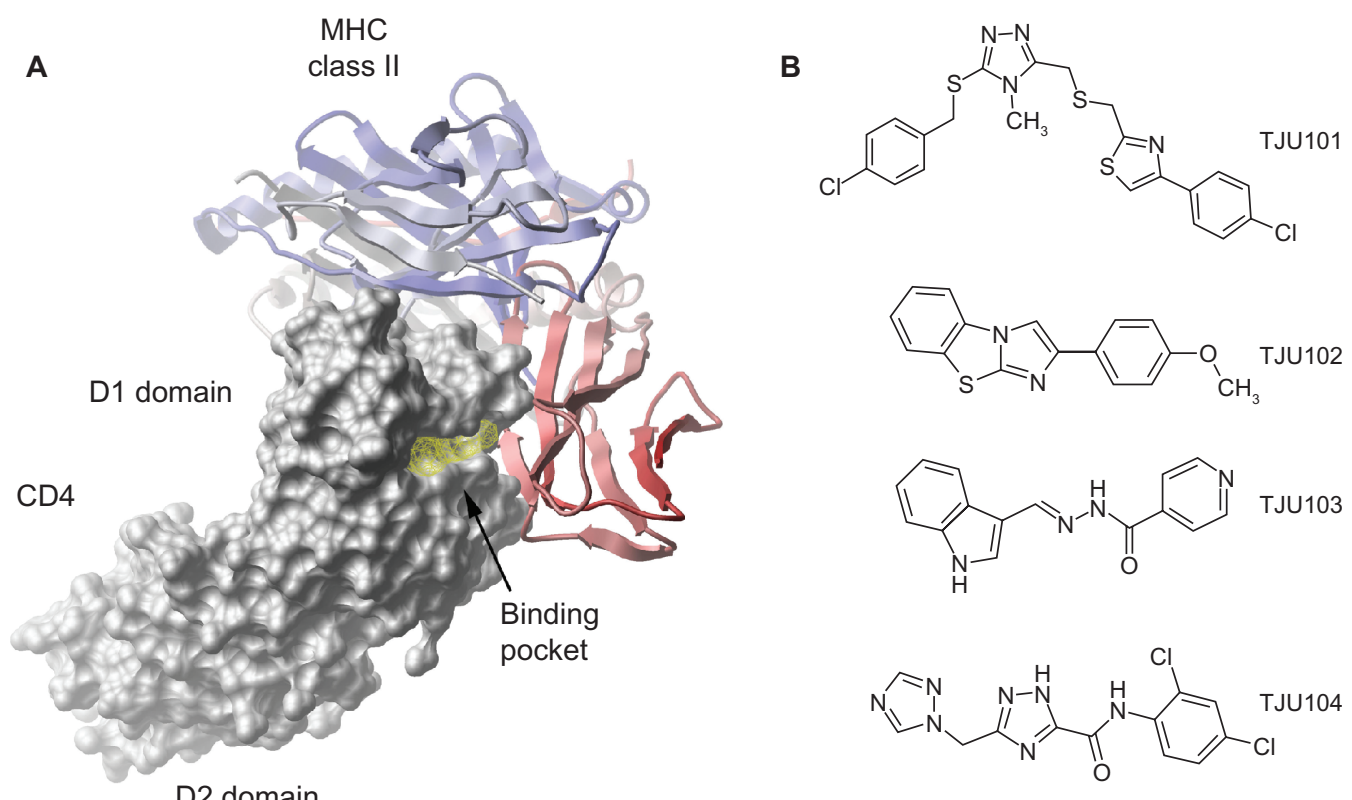

Figure 9 A) Surface pocket in the CD4 DI domain (PDB: Icdh) proposed to be involved in functional binding to MHC class II, ${ }^{147}$ and thus a target for small molecule inhibitor design; the same putative small-molecule pocket can be identified with the ICM Pocket Finder tool, ${ }^{261}$ although the actual binding site for the small-molecule inhibitors is unknown; the structure of MHC class II complexed to CD4 (PDB: Ijl4) is represented in ribbon, colored from N-term (blue) to C-term (red); B) Small inhibitors of CD4/MHC class II interaction.

Abbreviations: ICM, internal coordinate mechanics; MHC, major histocompatibility complex; PDB, Protein Data Bank. 
which then are able to phosphorylate dozens of proteins in vitro. Shapiro and colleagues applied a virtual screening approach to specifically target the ERK phosphorylation of two substrates: RSK-1 and ELK-1. The discovered compounds were able to inhibit the proliferation of several cancer cell lines in vitro. ${ }^{268} \mathrm{~A}$ recent study combined virtual fragment analysis and selection by molecular docking (using five different scoring functions) with an NMR-screening experiment called fluorine chemical shift anisotropy and exchange for screening (FAXS). The approach permitted the identification of a molecule displaying a strongly favorable binding enthalpy as tested by isothermal titration calorimetry (ITC), which suggested an enhanced selectivity for the v-src tyrosine kinase SH2 domain. Finally, computational modelling of the interaction nicely helped to explain the high binding enthalpy of this compound. ${ }^{269}$

\section{Drug design and regulation of PPI: clinical applications}

Very few of the designed molecule inhibitors of PPI have been clinically tested. One example is a synthetic cyclic heptapeptide that inhibits interaction between CD4 and MHC class II proteins and that has been approved by the United States Food and Drug Administration for a phase I clinical trial in graft-versus-host disease (GVHD) prophylaxis in bone marrow transplant patients. ${ }^{215,216}$ Another example is a new thrombopoetic growth factor, eltrombopag (or SB-497115), which is actually in phase III clinical trials as an oral and nonpeptide thrombopoetin receptor agonist for the treatment of idiopathic thrombocytopenic purpura. ${ }^{270-272}$ Genetech (San Francisco, CA, USA) is also developing pertussis toxin (IAP) antagonists, ${ }^{273}$ a novel class of cancer therapeutics, ${ }^{274}$ and one of the molecules is now in phase I clinical trials. ${ }^{275}$

Numerous factors can affect the output of an interaction network in a living organism. Some studies suggest than small changes in effector concentration can be more significant than absence or presence of a particular component, and the response can depend highly upon the biology of the system. ${ }^{159,276}$ The complexity of the response of the interaction networks in living organisms upon small changes in the environment makes the possibility of controlling signaling pathways with small compounds extremely challenging, although in the near future it will undoubtedly become one of the hottest areas in medicinal chemistry.

\section{Conclusions}

Targeting protein-protein interfaces with a small molecule is much more difficult than targeting a natural ligand pocket with another compound, due to the large and distributed set of interactions, the frequent lack of deep pockets, and the induced fit of the protein interfaces. A careful analysis of a protein-protein interface in search of putative small-molecule binding pockets, together with extensive computational protein-ligand docking simulations (virtual screening), will help to improve the rational design of PPI inhibitors. Computational prediction of "hot-spots" (for protein and ligand binding) at the surface of proteins can help to focus virtual screening or protein-ligand docking studies onto specific areas of a protein surface, and thus prioritize a large number of putative protein-protein interaction targets according to their potential to lead to a small molecule modulator. Finally, new improved protein-protein docking methods will be essential to predict the protein interfaces, and evaluate the PPI inhibition or oligomerization modulation capability of the selected compounds.

A combination of experimental and computational techniques, together with a deep knowledge of the determinants of protein-protein and protein-ligand interactions is necessary for the successful design of small compounds that can specifically modify PPI of therapeutic interest. The field is at its very early stage, but it constitutes a highly promising area of therapeutic proteomics.

\section{Disclosures}

The authors report no conflicts of interest in this work.

\section{References}

1. Perrakis A, Romier C. Assembly of protein complexes by coexpression in prokaryotic and eukaryotic hosts: an overview. Methods Mol Biol. 2008;426:247-256.

2. Suter B, Kittanakom S, Stagljar I. Two-hybrid technologies in proteomics research. Curr Opin Biotechnol. 2008;19:316-323.

3. Wells JA. Systematic mutational analyses of protein-protein interfaces. Methods Enzymol. 1991;202:390-411.

4. Bernstein FC, Koetzle TF, Williams GJ, et al. The Protein Data Bank: a computer-based archival file for macromolecular structures. $J \mathrm{Mol}$ Biol. 1977;112:535-542.

5. Vakser IA, Kundrotas P. Predicting 3D structures of protein-protein complexes. Curr Pharm Biotechnol. 2008;9:57-66.

6. Katchalski-Katzir E, Shariv I, Eisenstein M, Friesem AA, Aflalo C, Vakser IA. Molecular surface recognition: determination of geometric fit between proteins and their ligands by correlation techniques. Proc Natl Acad Sci U S A. 1992;89:2195-2199.

7. Kuntz ID, Blaney JM, Oatley SJ, Langridge R, Ferrin TE. A geometric approach to macromolecule-ligand interactions. $J$ Mol Biol. 1982;161:269-288.

8. Norel R, Petrey D, Wolfson HJ, Nussinov R. Examination of shape complementarity in docking of unbound proteins. Proteins. 1999;36:307-317.

9. Fernández-Recio J, Totrov M, Abagyan R. Soft protein-protein docking in internal coordinates. Protein Sci. 2002;11:280-291.

10. Bonvin AM. Flexible protein-protein docking. Curr Opin Struct Biol. 2006;16:194-200. 
11. Cheng TM, Blundell TL, Fernandez-Recio J. pyDock: electrostatics and desolvation for effective scoring of rigid-body protein-protein docking. Proteins. 2007;68:503-515.

12. Ladbury JE, Chowdhry BZ. Sensing the heat: the application of isothermal titration calorimetry to thermodynamic studies of biomolecular interactions. Chem Biol. 1996;3:791-801.

13. Stites W. Proteinminus signProtein Interactions: Interface Structure, Binding Thermodynamics, and Mutational Analysis. Chem Rev. 1997;97:1233-1250.

14. Radić Z, Kirchhoff PD, Quinn DM, McCammon JA, Taylor P. Electrostatic influence on the kinetics of ligand binding to acetylcholinesterase. Distinctions between active center ligands and fasciculin. J Biol Chem. 1997;272:23265-23277.

15. Velev OD, Kaler EW, Lenhoff AM. Protein interactions in solution characterized by light and neutron scattering: comparison of lysozyme and chymotrypsinogen. Biophys J. 1998;75:2682-2697.

16. Otzen DE, Fersht AR. Analysis of protein-protein interactions by mutagenesis: direct versus indirect effects. Protein Eng. 1999;12:41-45.

17. Lockhart DJ, Dong H, Byrne MC, Follettie MT, Gallo MV, Chee MS, et al. Expression monitoring by hybridization to high-density oligonucleotide arrays. Nat Biotechnol. 1996;14:1675-1680.

18. Uetz P, Hughes RE. Systematic and large-scale two-hybrid screens. Curr Opin Microbiol. 2000;3:303-308.

19. McCraith S, Holtzman T, Moss B, Fields S. Genome-wide analysis of vaccinia virus protein-protein interactions. Proc Natl Acad Sci US A. 2000;97:4879-4884.

20. Pellegrini M, Marcotte EM, Thompson MJ, Eisenberg D, Yeates TO. Assigning protein functions by comparative genome analysis: protein phylogenetic profiles. Proc Natl Acad Sci U S A. 1999;96: 4285-4288.

21. Marcotte EM, Pellegrini M, Ng HL, Rice DW, Yeates TO, Eisenberg D. Detecting protein function and protein-protein interactions from genome sequences. Science. 1999;285:751-753.

22. Enright AJ, Iliopoulos I, Kyrpides NC, Ouzounis CA. Protein interaction maps for complete genomes based on gene fusion events. Nature. 1999;402:86-90.

23. Marcotte EM, Pellegrini M, Thompson MJ, Yeates TO, Eisenberg D. A combined algorithm for genome-wide prediction of protein function. Nature. 1999;402:83-86.

24. Han DS, Kim HS, Jang WH, Lee SD, Suh JK. PreSPI: a domain combination based prediction system for protein-protein interaction. Nucleic Acids Res. 2004;32:6312-6320.

25. Li H, Li J, Wong L. Discovering motif pairs at interaction sites from protein sequences on a proteome-wide scale. Bioinformatics. 2006;22:989-996.

26. Pazos F, Valencia A. Similarity of phylogenetic trees as indicator of protein-protein interaction. Protein Eng. 2001;14:609-614.

27. Chen J, Hsu W, Lee ML, Ng SK. Increasing confidence of protein interactomes using network topological metrics. Bioinformatics. 2006;22:1998-2004.

28. Martin S, Roe D, Faulon JL. Predicting protein-protein interactions using signature products. Bioinformatics. 2005;21:218-226.

29. Juan D, Pazos F, Valencia A. High-confidence prediction of global interactomes based on genome-wide coevolutionary networks. Proc Natl Acad Sci U S A. 2008;105:934-939.

30. Harrington ED, Jensen LJ, Bork P. Predicting biological networks from genomic data. FEBS Lett. 2008;582:1251-1258.

31. Plewczyński D, Ginalski K. The interactome: predicting the proteinprotein interactions in cells. Cell Mol Biol Lett. 2009;14:1-22.

32. Shi TL, Li YX, Cai YD, Chou KC. Computational methods for protein-protein interaction and their application. Curr Protein Pept Sci. 2005;6:443-449.

33. Skrabanek L, Saini HK, Bader GD, Enright AJ. Computational prediction of protein-protein interactions. Mol Biotechnol. 2008;38:1-17.

34. Blaschke C, Andrade MA, Ouzounis C, Valencia A. Automatic extraction of biological information from scientific text: protein-protein interactions. Proc Int Conf Intell Syst Mol Biol. 1999:60-67.
35. Thomas J, Milward D, Ouzounis C, Pulman S, Carroll M. Automatic extraction of protein interactions from scientific abstracts. Pac Symp Biocomput. 2000:541-552.

36. Marcotte EM, Xenarios I, Eisenberg D. Mining literature for proteinprotein interactions. Bioinformatics. 2001;17:359-363.

37. Kim S, Shin SY, Lee IH, Kim SJ, Sriram R, Zhang BT. PIE: an online prediction system for protein-protein interactions from text. Nucleic Acids Res. 2008;36:W411-W415.

38. Costanzo MC, Hogan JD, Cusick ME, et al. The yeast proteome database (YPD) and Caenorhabditis elegans proteome database (WormPD): comprehensive resources for the organization and comparison of model organism protein information. Nucleic Acids Res. 2000;28:73-76.

39. Mewes HW, Frishman D, Gruber C, et al. MIPS: a database for genomes and protein sequences. Nucleic Acids Res. 2000;28:37-40.

40. Xenarios I, Rice DW, Salwinski L, Baron MK, Marcotte EM, Eisenberg D. DIP: the database of interacting proteins. Nucleic Acids Res. 2000;28:289-291.

41. Bader GD, Donaldson I, Wolting C, Ouellette BF, Pawson T, Hogue CW. BIND - The Biomolecular Interaction Network Database. Nucleic Acids Res. 2001;29:242-245.

42. Flajolet M, Rotondo G, Daviet L, et al. A genomic approach of the hepatitis $\mathrm{C}$ virus generates a protein interaction map. Gene. 2000;242:369-379.

43. Uetz P, Giot L, Cagney G, et al. A comprehensive analysis of protein-protein interactions in Saccharomyces cerevisiae. Nature. 2000;403:623-627.

44. Schwikowski B, Uetz P, Fields S. A network of protein-protein interactions in yeast. Nat Biotechnol. 2000;18:1257-1261.

45. Ito T, Tashiro K, Muta S, et al. Toward a protein-protein interaction map of the budding yeast: A comprehensive system to examine two-hybrid interactions in all possible combinations between the yeast proteins. Proc Natl Acad Sci U S A. 2000;97: 1143-1147.

46. Walhout AJ, Sordella R, Lu X, et al. Protein interaction mapping in C. elegans using proteins involved in vulval development. Science. 2000;287:116-122.

47. Rain JC, Selig L, De Reuse H, et al. The protein-protein interaction map of Helicobacter pylori. Nature. 2001;409:211-215.

48. Cusick ME, Klitgord N, Vidal M, Hill DE. Interactome: gateway into systems biology. Hum Mol Genet. 2005;14(Spec No 2):R171-R181.

49. Pacifico S, Liu G, Guest S, Parrish JR, Fotouhi F, Finley RL. A database and tool, IM Browser, for exploring and integrating emerging gene and protein interaction data for Drosophila. BMC Bioinformatics. 2006;7:195.

50. Parrish JR, Gulyas KD, Finley RL. Yeast two-hybrid contributions to interactome mapping. Curr Opin Biotechnol. 2006;17:387-393.

51. Parrish JR, Yu J, Liu G, Hines JA, Chan JE, Mangiola BA, et al. A proteome-wide protein interaction map for Campylobacter jejuni. Genome Biol. 2007;8:R130.

52. Thorn KS, Bogan AA. ASEdb: a database of alanine mutations and their effects on the free energy of binding in protein interactions. Bioinformatics. 2001;17:284-285.

53. Grosdidier S, Fernández-Recio J. Identification of hot-spot residues in protein-protein interactions by computational docking. $B M C$ Bioinformatics. 2008;9:447.

54. Young L, Jernigan RL, Covell DG. A role for surface hydrophobicity in protein-protein recognition. Protein Sci. 1994;3:717-729.

55. Argos P. An investigation of protein subunit and domain interfaces. Protein Eng. 1988;2:101-113.

56. Janin J, Miller S, Chothia C. Surface, subunit interfaces and interior of oligomeric proteins. J Mol Biol. 1988;204:155-164.

57. Jones S, Thornton JM. Protein-protein interactions: a review of protein dimer structures. Prog Biophys Mol Biol. 1995;63:31-65.

58. Jones S, Thornton JM. Principles of protein-protein interactions. Proc Natl Acad Sci U S A. 1996;93:13-20.

59. Jones S, Thornton JM. Prediction of protein-protein interaction sites using patch analysis. J Mol Biol. 1997;272:133-143. 
60. Jones S, Thornton JM. Analysis of protein-protein interaction sites using surface patches. J Mol Biol. 1997;272:121-132.

61. Chothia C, Janin J. Principles of protein-protein recognition. Nature. 1975;256:705-708.

62. Janin J, Chothia C. The structure of protein-protein recognition sites. J Biol Chem. 1990;265:16027-16030.

63. Lo Conte L, Chothia C, Janin J. The atomic structure of protein-protein recognition sites. J Mol Biol. 1999;285:2177-2198.

64. Zhou HX, Qin S. Interaction-site prediction for protein complexes: a critical assessment. Bioinformatics. 2007;23:2203-2209.

65. Gallet X, Charloteaux B, Thomas A, Brasseur R. A fast method to predict protein interaction sites from sequences. $J$ Mol Biol. 2000;302:917-926.

66. Zhou HX, Shan Y. Prediction of protein interaction sites from sequence profile and residue neighbor list. Proteins. 2001;44:336-343.

67. Ofran Y, Rost B. ISIS: interaction sites identified from sequence. Bioinformatics. 2007;23:e13-e16.

68. Landgraf R, Xenarios I, Eisenberg D. Three-dimensional cluster analysis identifies interfaces and functional residue clusters in proteins. $J \mathrm{Mol}$ Biol. 2001;307:1487-1502.

69. Neuvirth H, Raz R, Schreiber G. ProMate: a structure based prediction program to identify the location of protein-protein binding sites. $J \mathrm{Mol}$ Biol. 2004;338:181-199.

70. Fernandez-Recio J, Totrov M, Skorodumov C, Abagyan R. Optimal docking area: a new method for predicting protein-protein interaction sites. Proteins. 2005;58:134-143.

71. Casal E, Federici L, Zhang W, et al. The crystal structure of the BAR domain from human Bin1/amphiphysin II and its implications for molecular recognition. Biochemistry. 2006;45:12917-12928.

72. Bolanos-Garcia VM, Fernandez-Recio J, Allende JE, Blundell TL. Identifying interaction motifs in CK2beta - a ubiquitous kinase regulatory subunit. Trends Biochem Sci. 2006;31:654-661.

73. Fernández D, Vendrell J, Avilés FX, Fernández-Recio J. Structural and functional characterization of binding sites in metallocarboxypeptidases based on optimal docking area analysis. Proteins. 2007;68:131-144.

74. Chandran V, Poljak L, Vanzo NF, et al. Recognition and cooperation between the ATP-dependent RNA helicase RhlB and ribonuclease RNase E. J Mol Biol. 2007;367:113-132.

75. Stevens RC, Yokoyama S, Wilson IA. Global efforts in structural genomics. Science. 2001;294:89-92.

76. Todd AE, Marsden RL, Thornton JM, Orengo CA. Progress of structural genomics initiatives: an analysis of solved target structures. J Mol Biol. 2005;348:1235-1260.

77. Halperin I, Ma B, Wolfson H, Nussinov R. Principles of docking: An overview of search algorithms and a guide to scoring functions. Proteins. 2002;47:409-443.

78. Moreira IS, Fernandes PA, Ramos MJ. Protein-protein docking dealing with the unknown. J Comput Chem. 2009 May 21 [Epub ahead of print].

79. Langridge R, Ferrin TE, Kuntz ID, Connolly ML. Real-time color graphics in studies of molecular interactions. Science. 1981;211:661-666.

80. Connolly ML. Shape complementarity at the hemoglobin alpha 1 beta 1 subunit interface. Biopolymers. 1986;25:1229-1247.

81. Wodak SJ, Janin J. Computer analysis of protein-protein interaction. J Mol Biol. 1978;124:323-342.

82. Yue SY. Distance-constrained molecular docking by simulated annealing. Protein Eng. 1990;4:177-184.

83. Gabb HA, Jackson RM, Sternberg MJ. Modelling protein docking using shape complementarity, electrostatics and biochemical information. J Mol Biol. 1997;272:106-120.

84. Chen R, Weng Z. Docking unbound proteins using shape complementarity, desolvation, and electrostatics. Proteins. 2002;47:281-294.

85. Mintseris J, Pierce B, Wiehe K, Anderson R, Chen R, Weng Z. Integrating statistical pair potentials into protein complex prediction. Proteins. 2007;69:511-520.

86. Ritchie DW, Kemp GJ. Protein docking using spherical polar Fourier correlations. Proteins. 2000;39:178-194.
87. Helmer-Citterich M, Tramontano A. PUZZLE: a new method for automated protein docking based on surface shape complementarity. J Mol Biol. 1994;235:1021-1031.

88. Fischer D, Lin SL, Wolfson HL, Nussinov R. A geometry-based suite of molecular docking processes. J Mol Biol. 1995;248:459-477.

89. Gardiner EJ, Willett P, Artymiuk PJ. Protein docking using a genetic algorithm. Proteins. 2001;44:44-56.

90. Vakser IA, Aflalo C. Hydrophobic docking: a proposed enhancement to molecular recognition techniques. Proteins. 1994;20: 320-329.

91. Meyer M, Wilson P, Schomburg D. Hydrogen bonding and molecular surface shape complementarity as a basis for protein docking. $J \mathrm{Mol}$ Biol. 1996;264:199-210.

92. Bacon DJ, Moult J. Docking by least-squares fitting of molecular surface patterns. J Mol Biol. 1992;225:849-858.

93. Hart TN, Read RJ. A multiple-start Monte Carlo docking method. Proteins. 1992;13:206-222.

94. Cummings MD, Hart TN, Read RJ. Atomic solvation parameters in the analysis of protein-protein docking results. Protein Sci. 1995;4: 2087-2099.

95. Wallqvist A, Covell DG. Docking enzyme-inhibitor complexes using a preference-based free-energy surface. Proteins. 1996;25: 403-419.

96. Jiang F, Kim SH. "Soft docking": matching of molecular surface cubes. J Mol Biol. 1991;219:79-102.

97. Walls PH, Sternberg MJ. New algorithm to model protein-protein recognition based on surface complementarity. Applications to antibody-antigen docking. J Mol Biol. 1992;228:277-297.

98. Vakser IA. Protein docking for low-resolution structures. Protein Eng. 1995;8:371-377.

99. Ausiello G, Cesareni G, Helmer-Citterich M. ESCHER: a new docking procedure applied to the reconstruction of protein tertiary structure. Proteins. 1997;28:556-567.

100. Palma PN, Krippahl L, Wampler JE, Moura JJ. BiGGER: a new (soft) docking algorithm for predicting protein interactions. Proteins. 2000;39:372-384.

101. Betts MJ, Sternberg MJ. An analysis of conformational changes on protein-protein association: implications for predictive docking. Protein Eng. 1999;12:271-283.

102. Cherfils J, Duquerroy S, Janin J. Protein-protein recognition analyzed by docking simulation. Proteins. 1991;11:271-280.

103. Shoichet BK, Kuntz ID. Protein docking and complementarity. $J$ Mol Biol. 1991;221:327-346.

104. Weng Z, Vajda S, Delisi C. Prediction of protein complexes using empirical free energy functions. Protein Sci. 1996;5:614-626.

105. Jackson RM, Gabb HA, Sternberg MJ. Rapid refinement of protein interfaces incorporating solvation: application to the docking problem. J Mol Biol. 1998;276:265-285.

106. Camacho CJ, Gatchell DW, Kimura SR, Vajda S. Scoring docked conformations generated by rigid-body protein-protein docking. Proteins. 2000;40:525-537.

107. Camacho CJ. Modeling side-chains using molecular dynamics improve recognition of binding region in CAPRI targets. Proteins. 2005;60:245-251.

108. Gray JJ, Moughon S, Wang C, et al. Protein-protein docking with simultaneous optimization of rigid-body displacement and side-chain conformations. J Mol Biol. 2003;331:281-299.

109. Mazur AK, Abagyan RA. New methodology for computer-aided modelling of biomolecular structure and dynamics. 1. Non-cyclic structures. J Biomol Struct Dyn. 1989;6:815-832.

110. Abagyan RA, Mazur AK. New methodology for computeraided modelling of biomolecular structure and dynamics. 2 . Local deformations and cycles. J Biomol Struct Dyn. 1989;6: 833-845.

111. Abagyan R, Argos P. Optimal protocol and trajectory visualization for conformational searches of peptides and proteins. $J$ Mol Biol. 1992;225:519-532. 
112. Li Z, Scheraga HA. Monte Carlo-minimization approach to the multiple-minima problem in protein folding. Proc Natl Acad Sci US A. 1987;84:6611-6615.

113. Totrov M, Abagyan R. Detailed ab initio prediction of lysozymeantibody complex with 1.6 A accuracy. Nat Struct Biol. 1994;1: 259-263.

114. Strynadka NC, Eisenstein M, Katchalski-Katzir E, et al. Molecular docking programs successfully predict the binding of a betalactamase inhibitory protein to TEM-1 beta-lactamase. Nat Struct Biol. 1996;3:233-239.

115. Abagyan R, Totrov M, Kuznetsov D. ICM - A new method for protein modeling and design: Applications to docking and structure prediction from the distorted native conformation. J Comput Chem. 1994; $15: 488-506$.

116. Abagyan R, Totrov M. Biased probability Monte Carlo conformational searches and electrostatic calculations for peptides and proteins. $\mathrm{J} \mathrm{Mol}$ Biol. 1994;235:983-1002.

117. Goodford PJ. A computational procedure for determining energetically favorable binding sites on biologically important macromolecules. J Med Chem. 1985;28:849-857.

118. Totrov M, Abagyan R. Protein-ligand docking as an energy optimization problem. In: Raffa RB, editor. Drug-Receptor Thermodynamics: Introduction and Applications. Hoboken, NJ: John Wiley \& Sons; 2001. p. 603-624.

119. Fernández-Recio J, Totrov M, Abagyan R. Identification of proteinprotein interaction sites from docking energy landscapes. J Mol Biol. 2004;335:843-865.

120. Dominguez C, Boelens R, Bonvin AM. HADDOCK: a protein-protein docking approach based on biochemical or biophysical information. J Am Chem Soc. 2003;125:1731-1737.

121. Camacho CJ, Gatchell DW. Successful discrimination of protein interactions. Proteins. 2003;52:92-97.

122. Zacharias M. ATTRACT: protein-protein docking in CAPRI using a reduced protein model. Proteins. 2005;60:252-256.

123. Wang C, Schueler-Furman O, Baker D. Improved side-chain modeling for protein-protein docking. Protein Sci. 2005;14: 1328-1339.

124. Smith GR, Sternberg MJ, Bates PA. The relationship between the flexibility of proteins and their conformational states on forming protein-protein complexes with an application to protein-protein docking. J Mol Biol. 2005;347:1077-1101.

125. Grünberg R, Leckner J, Nilges M. Complementarity of structure ensembles in protein-protein binding. Structure. 2004;12:2125-2136.

126. May A, Zacharias M. Energy minimization in low-frequency normal modes to efficiently allow for global flexibility during systematic protein-protein docking. Proteins. 2008;70: 794-809.

127. Cuendet MA, Michielin O. Protein-protein interaction investigated by steered molecular dynamics: the TCR-pMHC complex. Biophys J. 2008;95:3575-3590.

128. Chen R, Mintseris J, Janin J, Weng Z. A protein-protein docking benchmark. Proteins. 2003;52:88-91.

129. Mintseris J, Wiehe K, Pierce B, et al. Protein-protein Docking Benchmark 2.0: an update. Proteins. 2005;60:214-216.

130. Hwang H, Pierce B, Mintseris J, Janin J, Weng Z. Protein-protein Docking Benchmark version 3.0. Proteins. 2008;73:705-709.

131. de Vries SJ, van Dijk DJ, Bonvin AM. WHISCY: what information does surface conservation yield? Application to data-driven docking. Proteins. 2006;63:479-489.

132. Méndez R, Leplae R, De Maria L, Wodak SJ. Assessment of blind predictions of protein-protein interactions: current status of docking methods. Proteins. 2003;52:51-67.

133. Méndez R, Leplae R, Lensink MF, Wodak SJ. Assessment of CAPRI predictions in rounds $3-5$ shows progress in docking procedures. Proteins. 2005;60:150-169.

134. Lensink MF, Méndez R, Wodak SJ. Docking and scoring protein complexes: CAPRI 3rd Edition. Proteins. 2007;69:704-718.
135. Wodak SJ, Méndez R. Prediction of protein-protein interactions: the CAPRI experiment, its evaluation and implications. Curr Opin Struct Biol. 2004;14:242-249.

136. Clackson T, Wells JA. A hot spot of binding energy in a hormonereceptor interface. Science. 1995;267:383-386.

137. Clackson T, Ultsch MH, Wells JA, de Vos AM. Structural and functional analysis of the 1:1 growth hormone:receptor complex reveals the molecular basis for receptor affinity. J Mol Biol. 1998;277:1111-1128.

138. Bogan AA, Thorn KS. Anatomy of hot spots in protein interfaces. J Mol Biol. 1998;280:1-9.

139. DeLano WL. Unraveling hot spots in binding interfaces: progress and challenges. Curr Opin Struct Biol. 2002;12:14-20.

140. $\mathrm{Hu} \mathrm{Z}, \mathrm{Ma} \mathrm{B}$, Wolfson $\mathrm{H}$, Nussinov R. Conservation of polar residues as hot spots at protein interfaces. Proteins. 2000;39:331-342.

141. Ma B, Elkayam T, Wolfson H, Nussinov R. Protein-protein interactions: structurally conserved residues distinguish between binding sites and exposed protein surfaces. Proc Natl Acad Sci US A. 2003;100:5772-5777.

142. Ofran Y, Rost B. Protein-protein interaction hotspots carved into sequences. PLoS Comput Biol. 2007;3:e119.

143. Kortemme T, Baker D. A simple physical model for binding energy hot spots in protein-protein complexes. Proc Natl Acad Sci U S A. 2002;99:14116-14121.

144. Kortemme T, Kim DE, Baker D. Computational alanine scanning of protein-protein interfaces. Sci STKE. 2004;2004:12.

145. Almlöf M, Aqvist J, Smalas AO, Bransdal BO. Probing the effect of poitn mutations at protein - protein interfaces with free energy calculations. Biophys J. 2006;90:433-442.

146. Moreira IS, Fernandes PA, Ramos MJ. Computational alanine scanning mutagenesis - an improved methodological approach. J Comput Chem. 2007;28:644-654.

147. Li S, Gao J, Satoh T, et al. A computer screening approach to immunoglobulin superfamily structures and interactions: discovery of small non-peptidic CD4 inhibitors as novel immunotherapeutics. Proc Natl Acad Sci U S A. 1997;94:73-78.

148. Miranker A, Karplus M. Functionality maps of binding sites: a multiple copy simultaneous search method. Proteins. 1991;11:29-34.

149. Caflisch A, Miranker A, Karplus M. Multiple copy simultaneous search and construction of ligands in binding sites: application to inhibitors of HIV-1 aspartic proteinase. J Med Chem. 1993;36:2142-2167.

150. Böhm HJ, Klebe $\mathrm{G}$. What can we learn from molecular recognition in protein-ligand complexes for the design of new drugs? Angew Chem Int Ed Engl. 1996;35:2588-2614.

151. English AC, Done SH, Caves LS, Groom CR, Hubbard RE. Locating interaction sites on proteins: the crystal structure of thermolysin soaked in 2\% to 100\% isopropanol. Proteins. 1999;37:628-640.

152. English AC, Groom CR, Hubbard RE. Experimental and computational mapping of the binding surface of a crystalline protein. Protein Eng. 2001;14:47-59.

153. Schubert C, Stultz C. The multi-copy simultaneous search methodology: a fundamental tool for structure-based drug design. J Comput Aided Mol Des. 2009;23:475-489.

154. Spencer RW. High-throughput screening of historic collections: observations on file size, biological targets, and file diversity. Biotechnol Bioeng. 1998;61:61-67.

155. Zutshi R, Brickner M, Chmielewski J. Inhibiting the assembly of protein-protein interfaces. Curr Opin Chem Biol. 1998;2:62-66.

156. Peczuh MW, Hamilton AD. Peptide and protein recognition by designed molecules. Chem Rev. 2000;100:2479-2494.

157. Cochran AG. Antagonists of protein-protein interactions. Chem Biol. 2000;7:R85-R94.

158. Sidhu SS, Fairbrother WF, Deshayes K. Exploring protein-protein interactions with phage display. Chembiochem. 2003;4:14-25.

159. Whitty A, Borysenko CW. Small molecule cytokine mimetics. Chem Biol. 1999;6:R107-R118.

160. Schooltink H, Rose-John S. Designing cytokine variants by phage-display. Comb Chem High Throughput Screen. 2005;8:173-179. 
161. Wrighton NC, Farrell FX, Chang R, Kashyap AK, Barbone FP, Mulcahy LS, et al. Small peptides as potent mimetics of the protein hormone erythropoietin. Science. 1996;273:458-464.

162. Livnah O, Johnson DL, Stura EA, et al. An antagonist peptide-EPO receptor complex suggests that receptor dimerization is not sufficient for activation. Nat Struct Biol. 1998;5:993-1004.

163. Cwirla SE, Balasubramanian P, Duffin DJ, et al. Peptide agonist of the thrombopoietin receptor as potent as the natural cytokine. Science. 1997;276:1696-1699.

164. Blume AJ, Beasley J, Goldstein NI. The use of peptides in Diogenesis: a novel approach to drug discovery and phenomics. Biopolymers. 2000;55:347-356.

165. Pillutla RC, Hsiao KC, Beasley JR, et al. Peptides identify the critical hotspots involved in the biological activation of the insulin receptor. J Biol Chem. 2002;277:22590-22594.

166. Nakamura GR, Reynolds ME, Chen YM, Starovasnik MA, Lowman HB. Stable "zeta" peptides that act as potent antagonists of the high-affinity IgE receptor. Proc Natl Acad Sci U S A. 2002;99:1303-1308.

167. Fan X, Flentke GR, Rich DH. Inhibition of HIV-1 protease by a subunit of didemnaketal A. J Am Chem Soc. 1998;120:8893-8894.

168. Stoll R, Renner C, Hansen S, et al. Chalcone derivatives antagonize interactions between the human oncoprotein MDM2 and p53. Biochemistry. 2001;40:336-344.

169. Vassilev LT, Vu BT, Graves B, et al. In vivo activation of the p53 pathway by small-molecule antagonists of MDM2. Science. 2004;303:844-848.

170. Leung DK, Yang Z, Breslow R. Selective disruption of protein aggregation by cyclodextrin dimers. Proc Natl Acad Sci U S A. 2000;97:5050-5053.

171. Chardin P, McCormick F. Brefeldin A: the advantage of being uncompetitive. Cell. 1999;97:153-155.

172. Kingston DG. Tubulin-interactive natural products as anticancer agents (1). J Nat Prod. 2009;72:507-515.

173. Kay BK, Paul JI. High-throughput screening strategies to identify inhibitors of protein-protein interactions. Mol Divers. 1996;1: 139-140.

174. Tian SS, Lamb P, King AG, Miller SG, Kessler L, Luengo JI, et al. A small, nonpeptidyl mimic of granulocyte-colony-stimulating factor. Science. 1998;281:257-259.

175. Doyle ML, Tian SS, Miller SG, Kessler L, Baker AE, BrighamBurke MR, et al. Selective binding and oligomerization of the murine granulocyte colony-stimulating factor receptor by a low molecular weight, nonpeptidyl ligand. J Biol Chem. 2003;278:9426-9434.

176. Kimura T, Kaburaki H, Tsujino T, Ikeda Y, Kato H, Watanabe Y. A non-peptide compound which can mimic the effect of thrombopoietin via c-Mpl. FEBS Lett. 1998;428:250-254.

177. Qureshi SA, Kim RM, Konteatis Z, Biazzo DE, Motamedi H, Rodrigues R, et al. Mimicry of erythropoietin by a nonpeptide molecule. Proc Natl Acad Sci U S A. 1999;96:12156-12161.

178. Biazzo DE, Motamedi H, Mark DF, Qureshi SA. A high-throughput assay to identify compounds that can induce dimerization of the erythropoietin receptor. Anal Biochem. 2000;278:39-45.

179. Zhang B, Salituro G, Szalkowski D, et al. Discovery of a small molecule insulin mimetic with antidiabetic activity in mice. Science. 1999;284:974-977.

180. Boger DL, Goldberg J, Satoh S, Ambroise Y, Cohen SB, Vogt PK. Non-amide-based combinatorial libraries derived from N-Boc iminodiacetic acid: Solution-phase synthesis of piperazinone libraries with activity against LEF-1ß/-catenin-mediated transcription. Helv Chim Acta. 2000;83:1825-1845.

181. Lepourcelet M, Chen YN, France DS, et al. Small-molecule antagonists of the oncogenic Tcf/beta-catenin protein complex. Cancer Cell. 2004;5:91-102.

182. McMillan K, Adler M, Auld DS, Baldwin JJ, Blasko E, Browne LJ, et al. Allosteric inhibitors of inducible nitric oxide synthase dimerization discovered via combinatorial chemistry. Proc Natl Acad Sci U S A. 2000;97:1506-1511.
183. Arkin MR, Wells JA. Small-molecule inhibitors of protein-protein interactions: progressing towards the dream. Nat Rev Drug Discov. 2004:3:301-317.

184. Kiessling A, Sperl B, Hollis A, Eick D, Berg T. Selective inhibition of c-Myc/Max dimerization and DNA binding by small molecules. Chem Biol. 2006;13:745-751.

185. Carter PH, Scherle PA, Muckelbauer JK, Voss ME, Liu RQ, Thompson LA, et al. Photochemically enhanced binding of small molecules to the tumor necrosis factor receptor-1 inhibits the binding of TNF-alpha. Proc Natl Acad Sci U S A. 2001;98:11879-11884.

186. Erbe DV, Wang S, Xing Y, Tobin JF. Small molecule ligands define a binding site on the immune regulatory protein B7.1. J Biol Chem. 2002;277:7363-7368.

187. Gao Y, Dickerson JB, Guo F, Zheng J, Zheng Y. Rational design and characterization of a Rac GTPase-specific small molecule inhibitor. Proc Natl Acad Sci U S A. 2004;101:7618-7623.

188. Schuffenhauer A, Ruedisser S, Marzinzik AL, et al. Library design for fragment based screening. Curr Top Med Chem. 2005;5:751-762.

189. Hajduk PJ, Greer J. A decade of fragment-based drug design: strategic advances and lessons learned. Nat Rev Drug Discov. 2007;6:211-219.

190. Oltersdorf T, Elmore SW, Shoemaker AR, et al. An inhibitor of Bcl-2 family proteins induces regression of solid tumours. Nature. 2005;435:677-681.

191. Erlanson DA, Wells JA, Braisted AC. Tethering: fragment-based drug discovery. Annu Rev Biophys Biomol Struct. 2004;33:199-223.

192. Braisted AC, Oslob JD, Delano WL, Hyde J, McDowell RS, Waal N, et al. Discovery of a potent small molecule IL-2 inhibitor through fragment assembly. J Am Chem Soc. 2003;125:3714-3715.

193. Raimundo BC, Oslob JD, Braisted AC, Hyde J, McDowell RS, Randal M, et al. Integrating fragment assembly and biophysical methods in the chemical advancement of small-molecule antagonists of IL-2: an approach for inhibiting protein-protein interactions. $J$ Med Chem. 2004;47:3111-3130.

194. Liang J, Edelsbrunner H, Woodward C. Anatomy of protein pockets and cavities: measurement of binding site geometry and implications for ligand design. Protein Sci. 1998;7:1884-1897.

195. Schneider H, Chaovapong W, Matthews DJ, et al. Homodimerization of erythropoietin receptor by a bivalent monoclonal antibody triggers cell proliferation and differentiation of erythroid precursors. Blood. 1997;89:473-482.

196. Yi J, Arthur JW, Dunbrack RL, Skalka AM. An inhibitory monoclonal antibody binds at the turn of the helix-turn-helix motif in the N-terminal domain of HIV-1 integrase. J Biol Chem. 2000;275:38739-38748.

197. Riethmüller G, Schneider-Gädicke E, Johnson JP. Monoclonal antibodies in cancer therapy. Curr Opin Immunol. 1993;5:732-739.

198. Cho MJ, Juliano R. Macromolecular versus small-molecule therapeutics: drug discovery, development and clinical considerations. Trends Biotechnol. 1996;14:153-158.

199. Saragovi HU, Fitzpatrick D, Raktabutr A, Nakanishi H, Kahn M, Greene MI. Design and synthesis of a mimetic from an antibody complementarity-determining region. Science. 1991;253:792-795.

200. Smythe ML, von Itzstein M. Design and synthesis of a biologically active antibody mimic based on an antibody-antigen crystal structure. J Am Chem Soc. 1994;116:2725-2733.

201. Chrunyk BA, Rosner MH, Cong Y, McColl AS, Otterness IG, Daumy GO. Inhibiting protein-protein interactions: a model for antagonist design. Biochemistry. 2000;39:7092-7099.

202. Hamuro Y, Calama MC, Park HS, Hamilton AD. A calixarene with four peptide loops: an antibody mimic for recognition of protein surfaces. Angew Chem Ed Engl. 1997;36:2680-2683.

203. Cunningham BC, Wells JA. Minimized proteins. Curr Opin Struct Biol. 1997;7:457-462.

204. Fairlie DP, West ML, Wong AK. Towards protein surface mimetics. Curr Med Chem. 1998;5:29-62.

205. Stigers KD, Soth MJ, Nowick JS. Designed molecules that fold to mimic protein secondary structures. Curr Opin Chem Biol. 1999;3:714-723. 
206. Dunican DJ, Doherty P. Designing cell-permeant phosphopeptides to modulate intracellular signaling pathways. Biopolymers. 2001;60:45-60.

207. Rubinstein M, Niv MY. Peptidic modulators of protein-protein interactions: progress and challenges in computational design. Biopolymers. 2009;91:505-513.

208. Ruoslahti E, Pierschbacher MD. Arg-Gly-Asp: a versatile cell recognition signal. Cell. 1986;44:517-518.

209. Stickel SK, Wang YL. Synthetic peptide GRGDS induces dissociation of alpha-actinin and vinculin from the sites of focal contacts. $J$ Cell Biol. 1988;107:1231-1239.

210. Schramm HJ, Boetzel J, Büttner J, et al. The inhibition of human immunodeficiency virus proteases by 'interface peptides'. Antiviral Res. 1996;30:155-170.

211. Schramm HJ, de Rosny E, Reboud-Ravaux M, Büttner J, Dick A, Schramm W. Lipopeptides as dimerization inhibitors of HIV-1 protease. Biol Chem. 1999;380:593-596.

212. Judice JK, Tom JY, Huang W, Wrin T, Vennari J, Petropoulos CJ, et al. Inhibition of HIV type 1 infectivity by constrained alpha-helical peptides: implications for the viral fusion mechanism. Proc Natl Acad Sci U S A. 1997;94:13426-13430.

213. Prasanna V, Bhattacharjya S, Balaram P. Synthetic interface peptides as inactivators of multimeric enzymes: inhibitory and conformational properties of three fragments from Lactobacillus casei thymidylate synthase. Biochemistry. 1998;37:6883-6893.

214. Ghosh I, Chmielewski J. A beta-sheet peptide inhibitor of E47 dimerization and DNA binding. Chem Biol. 1998;5:439-445.

215. Satoh T, Aramini JM, Li S, et al. Bioactive peptide design based on protein surface epitopes. A cyclic heptapeptide mimics CD4 domain 1 CC' loop and inhibits CD4 biological function. J Biol Chem. 1997;272:12175-12180.

216. Huang Z. Structural chemistry and therapeutic intervention of proteinprotein interactions in immune response, human immunodeficiency virus entry, and apoptosis. Pharmacol Ther. 2000;86:201-215.

217. Li S, Choksi S, Shan S, et al. Identification of the CD8 DE loop as a surface functional epitope. Implications for major histocompatibility complex class I binding and CD8 inhibitor design. $J$ Biol Chem. 1998;273:16442-16445.

218. Divita G, Restle T, Goody RS, Chermann JC, Baillon JG. Inhibition of human immunodeficiency virus type 1 reverse transcriptase dimerization using synthetic peptides derived from the connection domain. J Biol Chem. 1994;269:13080-13083.

219. Divita G, Baillon JG, Rittinger K, Chermann JC, Goody RS. Interface peptides as structure-based human immunodeficiency virus reverse transcriptase inhibitors. J Biol Chem. 1995;270:28642-28646.

220. Morris MC, Robert-Hebmann V, Chaloin L, et al. A new potent HIV-1 reverse transcriptase inhibitor. A synthetic peptide derived from the interface subunit domains. J Biol Chem. 1999;274:24941-24946.

221. Zutshi R, Chmielewski J. Targeting the dimerization interface for irreversible inhibition of HIV-1 protease. Bioorg Med Chem Lett. 2000;10:1901-1903.

222. Moss N, Beaulieu P, Duceppe JS, et al. Peptidomimetic inhibitors of herpes simplex virus ribonucleotide reductase with improved in vivo antiviral activity. $J$ Med Chem. 1996;39:4173-4180.

223. Dalgarno DC, Botfield MC, Rickles RJ. SH3 domains and drug design: ligands, structure, and biological function. Biopolymers. 1997; 43:383-400.

224. Ferrer M, Kapoor TM, Strassmaier T, et al. Selection of gp41-mediated HIV-1 cell entry inhibitors from biased combinatorial libraries of nonnatural binding elements. Nat Struct Biol. 1999;6:953-960.

225. Zhou G, Ferrer M, Chopra R, et al. The structure of an HIV-1 specific cell entry inhibitor in complex with the HIV-1 gp41 trimeric core. Bioorg Med Chem. 2000;8:2219-2227.

226. Zimmerman CN. Peptide and peptidomimetic inhibitors of VLA-4. Exp Opin Ther Patents. 1999;9:129-133.

227. Archibald SC, Head JC, Gozzard N, et al. Discovery and evaluation of potent, tyrosine-based alpha4beta1 integrin antagonists. Bioorg Med Chem Lett. 2000;10:997-999.
228. Archibald SC, Head JC, Linsley JM, Porter JR, Robinson MK, Shock A, et al. Discovery and evaluation of potent, cysteinebased alpha4beta1 integrin antagonists. Bioorg Med Chem Lett. 2000;10:993-995.

229. Fretz H, Furet P, Garcia-Echeverria C, Schoepfer J, Rahuel J. Structure-based design of compounds inhibiting Grb2-SH2 mediated protein-protein interactions in signal transduction pathways. Curr Pharm Des. 2000;6:1777-1796.

230. Walensky LD, Kung AL, Escher I, et al. Activation of apoptosis in vivo by a hydrocarbon-stapled BH3 helix. Science. 2004;305:1466-1470.

231. García-Echeverría $C$, Chène $P, B$ Bommers MJ, Furet $P$. Discovery of potent antagonists of the interaction between human double minute 2 and tumor suppressor p53. J Med Chem. 2000;43:3205-3208.

232. Orner BP, Ernst JT, Hamilton AD. Toward proteomimetics: terphenyl derivatives as structural and functional mimics of extended regions of an alpha-helix. J Am Chem Soc. 2001;123:5382-5383.

233. Tilley JW, Chen L, Fry DC, et al. Identification of a small molecule inhibitor of the IL2/IL2r $\alpha$ receptor interaction which binds to IL-2. J Am Chem Soc. 1997;119:7589-7590.

234. Sarabu R, Cooper JP, Cook CM, Gillespie P, Perrotta AV, Olson GL. Design and synthesis of small molecule interleukin-1 receptor antagonists based on a benzene template. Drug Des Discov. 1998;15:191-198.

235. McDowell RS, Gadek TR, Barker PL, et al. From peptide to nonpeptide. 1. The elucidation of a bioactive conformation of the arginine-glycine-aspartic acid recognition sequence. J Am Chem Soc. 1994;116:5069-5076.

236. McDowell RS, Blackburn BK, Gadek TR, et al. From peptide to nonpeptide. 2. The de novo design of potent, non-peptidal inhibitors of platelet aggregation based on a benzodiazepinedione scaffold. $J \mathrm{Am}$ Chem Soc. 1994;116:5077-5083.

237. Born G, Patrono C. Antiplatelet drugs. Br J Pharmacol. 2006; 147 Suppl 1:S241-S251.

238. Pandey A, Seroogy J, Volkots D, et al. Spirocyclic nonpeptide glycoprotein IIb-IIIa antagonists. Part 2: design of potent antagonists containing the 3-azaspiro[5.5] undecanes. Bioorg Med Chem Lett. 2001;11:1293-1296.

239. Smyth MS, Rose J, Mehrotra MM, et al. Spirocyclic nonpeptide glycoprotein IIb-IIIa antagonists. Part 1: design of potent and specific 3,9-di azaspiro[5.5]undecanes. Bioorg Med Chem Lett. 2001;11:1289-1292.

240. Deisenhofer J. Crystallographic refinement and atomic models of a human $\mathrm{Fc}$ fragment and its complex with fragment $\mathrm{B}$ of protein $\mathrm{A}$ from Staphylococcus aureus at 2.9- and 2.8-A resolution. Biochemistry. 1981;20:2361-2370.

241. Li R, Dowd V, Stewart DJ, Burton SJ, Lowe CR. Design, synthesis, and application of a protein A mimetic. Nat Biotechnol. 1998;16: 190-195.

242. Fazal MA, Roy BC, Sun S, Mallik S, Rodgers KR. Surface recognition of a protein using designed transition metal complexes. J Am Chem Soc. 2001;123:6283-6290.

243. Gardnerova M, Blanqué R, Gardner CR. The use of TNF family ligands and receptors and agents which modify their interaction as therapeutic agents. Curr Drug Targets. 2000;1:327-364.

244. Klabunde T, Petrassi HN, Oza VB, Raman P, Kelly JW, Sacchettini JC. Rational design of potent human transthyretin amyloid disease inhibitors. Nat Struct Biol. 2000;7:312-321.

245. Borchert TV, Abagyan R, Kishan KV, Zeelen JP, Wierenga RK. The crystal structure of an engineered monomeric triosephosphate isomerase, monoTIM: the correct modelling of an eight-residue loop. Structure. 1993;1:205-213.

246. Borchert TV, Abagyan R, Jaenicke R, Wierenga RX. Design, creation, and characterization of a stable, monomeric triosephosphate isomerase. Proc Natl Acad Sci U S A. 1994;91:1515-1518.

247. Guo Z, Zhou D, Schultz PG. Designing small-molecule switches for protein-protein interactions. Science. 2000;288:2042-2045.

248. Villoutreix BO, Renault N, Lagorce D, Sperandio O, Montes M, Miteva MA. Free resources to assist structure-based virtual ligand screening experiments. Curr Protein Pept Sci.2007;8:381-411. 
249. Zhong S, Macias AT, MacKerell AD. Computational identification of inhibitors of protein-protein interactions. Curr Top Med Chem. 2007;7:63-82.

250. Villoutreix BO, Bastard K, Sperandio O, et al. In silico-in vitro screening of protein-protein interactions: towards the next generation of therapeutics. Curr Pharm Biotechnol. 2008;9:103-122.

251. Sperandio O, Miteva MA, Segers K, Nicolaes GA, Villoutreix BO Screening outside the catalytic site: inhibition of macromolecular interactions through structure-based virtual ligand screening experiments Open Biochem J. 2008;2:29-37.

252. Zeng J, Treutlein HR. A method for computational combinatorial peptide design of inhibitors of Ras protein. Protein Eng. 1999;12:457-468.

253. Zeng J, Nheu T, Zorzet A, Catimel B, Nice E, Maruta H, et al. Design of inhibitors of Ras-Raf interaction using a computational combinatorial algorithm. Protein Eng. 2001;14:39-45.

254. Furet P, Gay B, García-Echeverría C, et al. Discovery of 3-aminobenzyloxycarbonyl as an N-terminal group conferring high affinity to the minimal phosphopeptide sequence recognized by the Grb2-SH2 domain. J Med Chem. 1997;40:3551-3556.

255. Furet P, Gay B, Caravatti G, et al. Structure-based design and synthesis of high affinity tripeptide ligands of the Grb2-SH2 domain. $J$ Med Chem. 1998;41:3442-3449.

256. Furet P, García-Echeverría C, Gay B, Schoepfer J, Zeller M, Rahuel J. Structure-based design, synthesis, and X-ray crystallography of a highaffinity antagonist of the Grb2-SH2 domain containing an asparagine mimetic. J Med Chem. 1999;42:2358-2363.

257. Sawyer TK. Src homology-2 domains: structure, mechanisms, and drug discovery. Biopolymers. 1998;47:243-261.

258. Bohm HJ. The computer program LUDI: A new method for the de novo design of enzyme inhibitors. $J$ Comput Aided Mol Des. 1992;6:61-78.

259. Ryu SE, Kwong PD, Truneh A, et al. Crystal structure of an HIV-binding recombinant fragment of human CD4. Nature. 1990;348:419-426.

260. Meng EC, Shoichet BK, Kuntz ID. Automated docking with grid-based energy evaluation. J Comput Chem. 1992;13:505-524.

261. Molsoft ICM 2.8 program manual. 2000 Available from: http:/www. molsoft.com/ Accessed January 10, 2009.

262. Kelly TA, Jeanfavre DD, McNeil DW, et al. Cutting edge: a small molecule antagonist of LFA-1-mediated cell adhesion. J Immunol. 1999; 163:5173-5177.

263. Last-Barney K, Davidson W, Cardozo M, et al. Binding site elucidation of hydantoin-based antagonists of LFA-1 using multidisciplinary technologies: evidence for the allosteric inhibition of a protein - protein interaction. J Am Chem Soc. 2001;123:5643-5650.
264. Gorczynski MJ, Grembecka J, Zhou Y, et al. Allosteric inhibition of the protein-protein interaction between the leukemia-associated proteins Runx1 and CBFbeta. Chem Biol. 2007;14:1186-1197.

265. Huang N, Nagarsekar A, Xia G, Hayashi J, MacKerell AD. Identification of non-phosphate-containing small molecular weight inhibitors of the tyrosine kinase p56 Lck SH2 domain via in silico screening against the pY +3 binding site. J Med Chem. 2004;47:3502-3511.

266. Macias AT, Mia MY, Xia G, Hayashi J, MacKerell AD. Lead validation and SAR development via chemical similarity searching; application to compounds targeting the $\mathrm{pY}+3$ site of the $\mathrm{SH} 2$ domain of p56lck. J Chem Inf Model. 2005;45:1759-1766.

267. Markowitz J, Chen I, Gitti R, et al. Identification and characterization of small molecule inhibitors of the calcium-dependent S100B-p53 tumor suppressor interaction. J Med Chem. 2004;47:5085-5093.

268. Hancock CN, Macias A, Lee EK, Yu SY, Mackerell AD, Shapiro P. Identification of novel extracellular signal-regulated kinase docking domain inhibitors. J Med Chem. 2005;48:4586-4595.

269. Taylor JD, Gilbert PJ, Williams MA, Pitt WR, Ladbury JE. Identification of novel fragment compounds targeted against the $\mathrm{pY}$ pocket of v-Src SH2 by computational and NMR screening and thermodynamic evaluation. Proteins. 2007;67:981-990.

270. Luengo JL, Duffy KJ, Shaw AN, et al. Discovery of SB-497115, a small-molecule thrombopoietin (TPO) receptor agonist for the treatment of thrombocytopenia. ASH Annual Meeting Abstracts. Blood. 2004;104:Abstract 2910.

271. Erickson-Miller CL, Delorme E, Tian SS, et al. Preclinical activity of eltrombopag (SB-497115), an oral, nonpeptide thrombopoietin receptor agonist. Stem Cells. 2009;27:424-430.

272. Lam MS. Second generation thrombopoietin agents for treatment of chronic idiopathic thrombocytopenic purpura in adults. J Oncol Pharm Pract. 2009 June 12 [Epub ahead of print].

273. Cohen F, Alicke B, Elliott LO, et al. Orally bioavailable antagonists of inhibitor of apoptosis proteins based on an azabicyclooctane scaffold. J Med Chem. 2009;52:1723-1730.

274. Vucic D, Fairbrother WJ. The inhibitor of apoptosis proteins as therapeutic targets in cancer. Clin Cancer Res. 2007;13:5995-6000.

275. Varfolomeev E, Blankenship JW, Wayson SM, et al. IAP antagonists induce autoubiquitination of c-IAPs, NF-kappaB activation, and TNFalpha-dependent apoptosis. Cell. 2007;131:669-681.

276. Bhalla US, Iyengar R. Emergent properties of networks of biological signaling pathways. Science. 1999;283:381-387.

Advances and Applications in Bioinformatics and Chemistry

\section{Publish your work in this journal}

Advances and Applications in Bioinformatics and Chemistry is an international, peer-reviewed open-access journal that publishes articles in the following fields: Computational biomodelling; Bioinformatics; Computational genomics; Molecular modelling; Protein structure modelling and structural genomics; Systems Biology; Computational

\section{Dovepress}

Biochemistry; Computational Biophysics; Chemoinformatics and Drug Design; In silico ADME/Tox prediction. The manuscript management system is completely online and includes a very quick and fair peerreview system, which is all easy to use. Visit http://www.dovepress.com/ testimonials.php to read real quotes from published authors. 